\title{
Zonal Fluxes in the Deep Water Layers of the Western South Atlantic Ocean*
}

\author{
Michal VAniceK ${ }^{+}$ANd Gerold SiedleR\# \\ Institut für Meereskunde, Kiel, Germany
}

(Manuscript received 16 March 2001, in final form 21 November 2001)

\begin{abstract}
Zonal transports of North Atlantic Deep Water (NADW) in the South Atlantic are determined. For this purpose the circulation of intermediate and deep water masses is established on the basis of hydrographic sections from the World Ocean Circulation Experiment (WOCE) and some pre-WOCE sections, using temperature, salinity, nutrients, and anthropogenic tracers. Multiple linear regression is applied to infer missing parameters in the bottle dataset. A linear box-inverse model is used for a set of closed boxes given by sections and continental boundaries. After performing a detailed analysis of water mass distribution, 11 layers are prescribed. Neutral density surfaces are selected as layer interfaces, thus improving the description of water mass distribution in the transition between the subtropical and subpolar latitudes. Constraints for the inverse model include integral meridional salt and phosphorus transports, overall salt and silica conservation, and transports from moored current meter observations. Inferred transport numbers for the mean meridional thermohaline overturning are given. Persistent zonal NADW transport bands are found in the western South Atlantic, in particular eastward flow of relatively new NADW between $20^{\circ}$ and $25^{\circ} \mathrm{S}$ and westward flow of older NADW to the north of this latitude range. The axis of the eastward transport band corresponds to the core of property distributions in this region, suggesting Wüstian flow. Part of the eastward flow appears to cross the Mid-Atlantic Ridge at the Rio de Janeiro Fracture Zone. Results are compared qualitatively with deep float observations and results from general circulation models.
\end{abstract}

\section{Introduction}

The South Atlantic Ocean serves as the passage between the key water mass formation regions in the global ocean. Cold North Atlantic Deep Water (NADW), having been formed by convection and mixing in the northern North Atlantic (see Dickson and Brown 1994), flows southward at depth, and the compensating return flow at intermediate and shallow levels transports warmer water from the Pacific and Indian Oceans to the North Atlantic (see Gordon 1986; Rintoul 1991). Also, cold subpolar and polar water masses, including Weddell Sea Water and Circumpolar Deep Water (CDW) (see Orsi et al. 1999), arrive from the south and contribute to the global overturning cell. The related large-scale circulation patterns and quantitative transports from a great number of studies were assembled and reviewed by Schmitz (1995, 1996a,b).

* WOCE Contribution.

+ Current affiliation: Woods Hole Oceanographic Institution, Woods Hole, Massachusetts.

\# Additional affiliation: Instituto Canario de Ciencias Marinas, Telde, Spain.

Corresponding author address: M. Vanicek, Woods Hole Oceanographic Institution, 360 Woods Hole Road, MS\#21, Woods Hole, MA 02543.

E-mail: mvanicek@whoi.edu.
The first systematic studies of the basinwide South Atlantic water mass distribution and circulation structure were performed on the Meteor in 1925-27 (Wüst 1935; Defant 1941) and then during the International Geophysical Year in 1957-58 (Fuglister 1960). Reid (1989), on the basis of high-quality hydrographic data from the South Atlantic available in the 1980s, gave a presentation of geostrophic flow patterns and transports that has been a benchmark for later studies. More recently, the inclusion of new data resulted in identifying more complex circulation patterns in the intermediatedepth and the deep South Atlantic (e.g., Speer and Zenk 1993; Tsuchiya et al. 1994; Friedrichs et al. 1994; De Madron and Weatherly 1994; Larqué et al. 1997; Stramma and England 1999).

Wüst (1935) had offered a "spreading" hypothesis for the flow, with water masses extending down property gradients. A tongue-shaped distribution of a water property then indicates water mass transport along the axis of the tongue. The question needs to be answered, with the help of geostrophic current calculations and/or direct current measurements, whether the real flow is downgradient or normal to the gradient as is often found in geostrophic flow, that is, following the boundaries of property tongues.

This question is also related to the role of meridional versus zonal transports in the South Atlantic and to the 
TABLE 1. Characteristic property extrema indicating different water masses; Min: minimum, MAX: maximum, $\uparrow:$ increase towards bottom, $\downarrow$ : decrease towards bottom. For water mass definitions see text.

\begin{tabular}{|c|c|c|c|c|c|c|c|c|}
\hline Water mass & Temperature & $S$ & $\mathrm{O}_{2}$ & $\mathrm{SiO}_{4}$ & $\mathrm{PO}_{4}$ & $\mathrm{CFC}$ & $\begin{array}{l}\text { Terrig. } \\
\text { helium }\end{array}$ & $\begin{array}{l}\text { Potential } \\
\text { vorticity }\end{array}$ \\
\hline $\mathrm{SF}(\mathrm{CW})$ & - & - & Min & - & - & - & - & - \\
\hline AAIW & - & Min & MAX & - & - & MAX & - & Min \\
\hline UCDW & Min & - & Min & MAX & - & Min & MAX & - \\
\hline UNADW & MAX & MAX & - & Min & Min & MAX & Min* & - \\
\hline $\mathrm{LSW} * *$ & - & - & MAX & - & - & - & $\operatorname{Min} *$ & - \\
\hline LNADW-old** & - & - & Min & - & - & Min & $\operatorname{Min} *$ & - \\
\hline OLNADW** & - & - & MAX & - & - & MAX & Min* & - \\
\hline LCDW & - & - & Min & MAX & - & - & MAX & - \\
\hline AABW & $\downarrow$ & $\downarrow$ & - & MAX & - & $\uparrow$ & - & - \\
\hline
\end{tabular}

* This minimum can be hidden above the MAR crest.

** NADW layers were subdivided following Rhein et al. (1995): UNADW corresponds approximately to SUNADW; MNADW consists of LSW and LNADW-old, where the latter is mostly derived from GFZW (Gibbs Fracture Zone water).

possibility of deep water crossing the Mid-Atlantic Ridge (MAR). As an example, Wüst (1935) pointed out that oxygen-rich NADW protruded from the South American continental slope eastward at about $20^{\circ} \mathrm{S}$ near the Vitória-Trindade Ridge. Does this represent a Wüstian flow along the tongue's axis? Zonal branching in that region has been suggested in various published circulation schemes (Tsuchiya et al. 1994; De Madron and Weatherly 1994; Friedrichs et al. 1994; Zangenberg and Siedler 1998). Especially in the first study of the water mass distributions along the $25^{\circ} \mathrm{W}$ SAVE (A16) section, Tsuchiya et al. (1994) highlighted that the southward spreading of NADW is interrupted by domains of intensified circumpolar characteristics and related this to the basin-scale gyre circulation. The core of high-salinity, high-oxygen, low-nutrient water at $18^{\circ}-25^{\circ} \mathrm{S}$ appears to be the southern limb of the proposed anticyclonic gyre (Tsuchiya et al. 1994). In most of these patterns the NADW does not cross the MAR and instead recirculates to the north. Speer et al. (1995), however, presented results indicating the upper NADW flowing zonally across the MAR and reaching the Walvis Ridge (see also Warren and Speer 1991). Recent float observations in the World Ocean Circulation Experiment (WOCE) showed that, away from the western boundary, the zonal flow dominates the meridional flow, with some floats heading toward the MAR between $20^{\circ}$ and $25^{\circ} \mathrm{S}$ (Hogg and Owens 1999; Hogg 2001). The trajectory of the float traveling farthest to the east ended at $22.2^{\circ} \mathrm{S}$, $12.8^{\circ} \mathrm{W}$ exactly over the MAR crest in the Rio de Janeiro Fracture Zone.

Several recent analyses have dealt with meridional fluxes in the South Atlantic (e.g., Saunders and King 1995; Macdonald and Wunsch 1996; Speer et al. 1996; Macdonald 1998; Holfort et al. 1998; Holfort and Siedler 2001). In the present study we want to provide some insight into the zonal water mass transport regimes at midlatitudes that exist in this broad meridional passage for the thermohaline circulation.

Identifying water mass layers appropriately will be a prerequisite. A water mass is a body of water with com- mon origin and spreading history, and its properties are usually an indicator for the imprint of key properties at the surface. Water masses can be characterized by property distributions and particularly by extrema in properties that persist even after considerable dilution with surrounding waters. Some extrema, however, are lost under way due to dilution after transport over large distances or due to consumption (e.g., in oxygen concentration). Property changes may also be caused by the addition of substances in the abyssal ocean (e.g., silica or terrigenic helium, which changes the $\delta^{3} \mathrm{He}$ used here). Delta ${ }^{3} \mathrm{He}\left(\delta^{3} \mathrm{He}\right)$ is the relative deviation of the ${ }^{3} \mathrm{He} /$ ${ }^{4} \mathrm{He}$ isotopic ratio from that of atmospheric $\mathrm{He}$ (e.g., Roether et al. 1998). Extrema characterizing specific water masses in the South Atlantic are summarized in Table 1.

Although anthropogenic tracers have a time-dependent input function, they can be used in a similar way to identify water masses from extrema. For example, recently ventilated water masses may not only show increased values of oxygen, but also maxima of chlorofluorocarbons (CFCs). On the other hand, old water masses will have distinct minima or show a complete absence of CFCs, similar to the oxygen loss in water when transported over long distances without contact with surface water.

We want to remind the reader that deep and abyssal water masses entering the South Atlantic from the south are characterized by maxima in silicate concentrations, and those arriving with the Antarctic Circumpolar Current (ACC) in addition by high values of $\delta^{3} \mathrm{He}$, contrary to water masses from the north which can be traced by low silica and terrigenic helium concentrations.

Reid et al. (1977) and Peterson and Whitworth (1989) provided descriptions of water masses, as characterized by property extrema, for moderate and high latitudes in the western South Atlantic. Reid (1989) and recently Stramma and England (1999) summarized the water masses in the whole South Atlantic. We will use the traditional and also additional tracers (CFCs, $\delta^{3} \mathrm{He}$ ) to identify further details of water mass distributions in the 


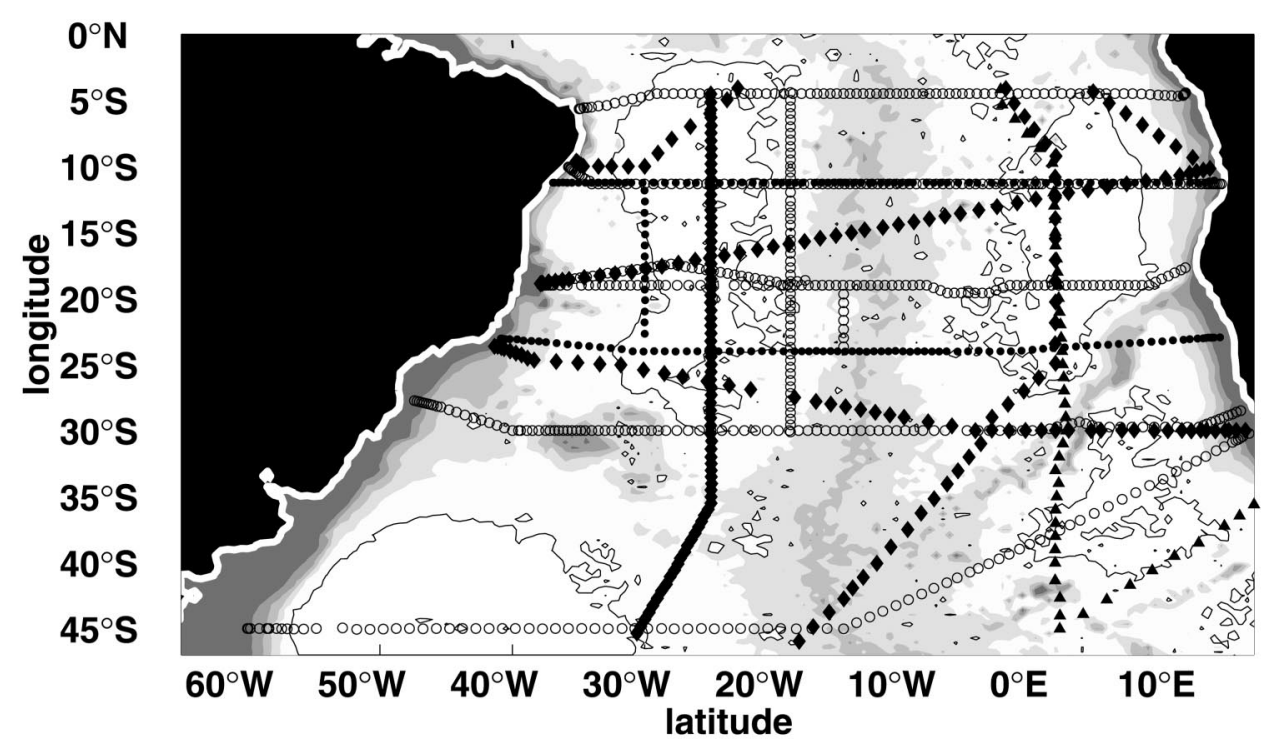

FIG. 1. Hydrographic sections used in this study: Open circle: WOCE, solid diamond: SAVE, solid circle: Oceanus 133, and solid triangle: AJAX; for details see Table 2. The 5000-m isobath (solid thin line) denotes the deep basins: Brazil Basin (NW), Angola Basin (NE), Argentine Basin (SW), and Cape Basin (SE). Bathymetry shallower than $4000 \mathrm{~m}$ is shaded with a $1000-\mathrm{m}$ step.

South Atlantic with the aim of providing an improved layer selection for the subsequent inverse analysis. This study will then deal with the deep water masses in the South Atlantic. We will first present the selected dataset and will then concentrate on the deep water (NADW + CDW).

\section{Dataset}

Data from a total of 19 high-quality hydrographic sections are used (Fig. 1, Table 2). They include the majority of WOCE one-time sections in the South At- lantic, in particular all five WOCE zonal sections A07, A08, A09, A10, and A11 and the two meridional WOCE sections A15 and A16. Some pre-WOCE sections were added to fill in for the meridional WOCE sections that were not yet available at the time when this analysis was carried out. The chosen sections subdivide the South Atlantic into 73 closed boxes where conservation requirements can be imposed.

The boxes are not treated equally. In particular we distinguish between "main" and "secondary" boxes. The first ones are eight large continent-to-continent boxes defined by pairs of cross-Atlantic zonal sections and

TABLE 2. Hydrographic sections in the South Atlantic used in the present study. The symbols in the first column correspond to those in Fig. 1. CTDO: temperature, salinity, pressure and $\mathrm{O}_{2}$ from CTD; Nutr: nutrients from bottles; CFC: freon; and He: helium.

\begin{tabular}{|c|c|c|c|c|c|c|}
\hline Symbol & $\begin{array}{l}\text { WOCE } \\
\text { section }\end{array}$ & Cruise & Location & Vessel & $\begin{array}{l}\text { Time period } \\
\text { month/year }\end{array}$ & $\begin{array}{l}\text { Available } \\
\text { properties }\end{array}$ \\
\hline O & A07 & CITHER1/1 & Zonal $4.5^{\circ} \mathrm{S}$ & L'Atalante & $1-2 / 93$ & CTDO, Nutr, CFC \\
\hline 0 & A08 & M28/1 & Zonal $11^{\circ} \mathrm{S}$ & Meteor & $3-5 / 94$ & CTDO, Nutr, CFC, He \\
\hline O & A09 & M15/3 & Zonal $19^{\circ} \mathrm{S}$ & Meteor & $2-3 / 91$ & CTDO, Nutr, CFC, He \\
\hline O & A09 & M15/3 & Meridional $15^{\circ} \mathrm{W}$ & Meteor & $2-3 / 91$ & CTDO, Nutr, CFC, He \\
\hline O & A10 & $\mathrm{M} 22 / 5$ & Zonal $30^{\circ} \mathrm{S}$ & Meteor & $12 / 92-1 / 93$ & CTDO, Nutr, CFC, He \\
\hline O & A11 & DI199/1 & Zonal $45^{\circ}-30^{\circ} \mathrm{S}$ & Discovery & $12 / 92-2 / 93$ & CTDO, Nutr, CFC \\
\hline O & A15 & $6 \mathrm{~N} 142 / 3$ & Meridional $19^{\circ} \mathrm{W}$ & Knorr & $4-5 / 94$ & CTDO, Nutr \\
\hline O & AR15 & $6 \mathrm{~N} 142 / 3$ & Zonal $19^{\circ} \mathrm{S}$ & Knorr & $4-5 / 94$ & CTDO, Nutr \\
\hline$\diamond$ & - & SAVE/1 & $8^{\circ}-4^{\circ} \mathrm{S}$ & Knorr & $11-12 / 87$ & CTDO, Nutr, CFC \\
\hline$\diamond$ & - & SAVE/2 & Zonal $19^{\circ}-10^{\circ} \mathrm{S}$ & Knorr & $12 / 87-1 / 88$ & CTDO, Nutr, CFC \\
\hline$\diamond$ & - & $\mathrm{SAVE} / 2$ & $10^{\circ}-4^{\circ} \mathrm{S}$ & Knorr & $12 / 87-1 / 88$ & CTDO, Nutr, CFC \\
\hline$\diamond$ & - & SAVE/3 & $25^{\circ} \mathrm{S}$ and $0^{\circ} \mathrm{W}$ & Knorr & $1-3 / 88$ & CTDO, Nutr, CFC \\
\hline$\diamond$ & - & SAVE/4 & $30^{\circ} \mathrm{S}$ and southerly & Melville & $12 / 88-1 / 89$ & CTDO, Nutr, CFC \\
\hline$\diamond$ & A16S & SAVE/5 & Meridional $25^{\circ}-36^{\circ} \mathrm{W}$ & Melville & $1-3 / 89$ & CTDO, Nutr, CFC \\
\hline$\diamond$ & A16C & SAVE/6 & Meridional $25^{\circ} \mathrm{W}$ & Melville & $3-4 / 89$ & CTDO, Nutr, CFC \\
\hline$\bullet$ & - & OCE133/3 & Meridional $30^{\circ} \mathrm{W}$ & Oceanus & $2-3 / 83$ & CTDO, Nutr \\
\hline$\bullet$ & - & OCE133/4 & Zonal $23^{\circ} \mathrm{S}$ & Oceanus & $2-3 / 83$ & CTDO, Nutr \\
\hline$\bullet$ & - & OCE133/7 & Zonal $11^{\circ} \mathrm{S}$ & Oceanus & $3-4 / 83$ & CTDO, Nutr \\
\hline $\mathbf{\Delta}$ & - & AJAX1 & Meridional approx. $0^{\circ}$ & Knorr & $10-11 / 83$ & CTD-, Nutr, CFC \\
\hline
\end{tabular}


TABLE 3. Input parameters of the MLR for inferring missing parameters in the bottle dataset and for interpolating the bottle data onto the CTD profiles. Apparent oxygen utilisation (AOU) was calculated after Broecker and Peng (1982, p. 131). Rows are ordered according to the sequence in which the parameters were interpolated. The " \pm " distances from the location of the missing parameter (latitude, longitude, and depth) spanning the box within which the input parameters and measured values of missing properties were taken are shown in the last two columns. The percentages correspond to a vertical enlargement of the value in percent of the actual in-situ depth (e.g., $\mathrm{O}_{2}$ at $2000 \mathrm{~m}$ is interpolated from values between $1450 \mathrm{~m}$ and $2550 \mathrm{~m}$ ). For a description see text.

\begin{tabular}{lllr}
\hline \hline \multicolumn{1}{c}{ Source } & $\begin{array}{c}\text { Parameter to } \\
\text { interpolate }\end{array}$ & \multicolumn{1}{c}{$\begin{array}{c}\text { As a linear combination } \\
\text { of the parameters }\end{array}$} & $\begin{array}{c} \pm \text { Horizontal } \\
\Delta \varphi / \Delta \lambda\end{array}$ \\
\hline Bottle & $\mathrm{O}_{2}$ & Pressure, $S, \theta, \sigma_{\theta}$ & $2.5^{\circ} / 2.5^{\circ}$ \\
Bottle & Nutrients & $S, \theta, \mathrm{AOU}, \mathrm{NO}_{3}, \mathrm{PO}_{4}, \mathrm{SiO}_{4}$ & $2.5^{\circ} / 2.5^{\circ}$ \\
Bottle & Tracer & $S, \theta, \mathrm{AOU}, \mathrm{SiO}_{4}$ & $2.5^{\circ} / 2.5^{\circ}$ \\
CTD & All bottle par. & $S, \theta, \sigma_{\theta,}, \mathrm{AOU}, \mathrm{O}_{2}$ & $150 \mathrm{~m}+20 \%+20 \%$ \\
\hline
\end{tabular}

the continental boundaries. This kind of box is often used in global inverses for studying the meridional overturning (e.g., Macdonald 1998; Ganachaud and Wunsch 2000). Meridional sections divide the main boxes into smaller secondary boxes. To minimize the number of nonsynoptic crossovers (to two per box), the secondary boxes were defined by the two zonal sections and only one meridional section and the boundary, which was nearer to the meridional section, where possible. This approach increases the box area toward the interior of the basin and reduces the error due to the temporal variability compared to the method where the secondary boxes are ordered along the zonal section pair, having mostly four nonsynoptic crossovers.

A special case of a main box was defined by the pair of repeat sections at $11^{\circ} \mathrm{S}$ (A08 and Oceanus $133 \mathrm{sec}-$ tions). By setting up the main box we consequently followed the strategy used for the other section pairs (advection of a property into a main box through one zonal section is balanced by flux out of the box through the other zonal section). The difference to the other main boxes arises from the fact that this particular box does not have any significant horizontal area that could be divided into secondary boxes. Therefore this is the only main box without secondary boxes. On the other hand, the secondary boxes on both sides of $11^{\circ} \mathrm{S}$ were defined twice, using A08 as well as Oceanus 133 at $11^{\circ} \mathrm{S}$ and, for example, A07 section as the northern boundary. Similar double definition of secondary boxes occurs around $0^{\circ}$, where a part of the section along the Greenwich meridian was repeated during AJAX1 and SAVE3 experiments. Those meridional sections do not have influence on the main boxes. From the total of 73 boxes of this inversion, 13 are framed by two sections (where 8 are main boxes), 55 by three sections (the bulk of the secondary boxes), and only 5 boxes are defined using four sections.

Table 2 gives an overview of the data available in individual sections. Some parameter values were missing on certain stations or whole sections (mostly tracer data). In order to obtain a consistent complete dataset, a multiple linear regression (MLR, after Holfort et al. 1998) was applied. This interpolation method makes use of the correlation between different parameters and enabled us to infer single missing values and also to in- clude nutrient and tracer data in the inverse model with a spatial resolution corresponding to the CTD data.

Table 3 shows the parameters used to set up a linear combination representing the unknown (missing) property, and it shows also the " \pm " distance from the location of the missing parameter (depth, latitude, and longitude of the bottle sample) within which the input parameters and measured values of missing properties were taken for the linear equation system. Because we can assume a decrease of property gradients toward the bottom, the vertical distance was increased by $20 \%$ or $15 \%$ of the in situ depth. This leads to thin layers in the high gradient upper ocean, which is usually better sampled, and somewhat thicker layers in the nearly homogeneous part of the water column near the bottom, which provides a sufficient number of parameters in this not so well sampled regime. The horizontal distances in both the meridional and the zonal directions $(\Delta \varphi$, $\Delta \lambda$ ) were set to $2.5^{\circ}$ to fill the gaps in bottle data, and to $1.5^{\circ}$ when interpolating them onto the CTD dataset, respectively. Such scales are much smaller than the basinwide scale of the inversion and the coefficients of the linear combination vary with geographical location and depth. Therefore the parameters that were linearly independent before applying the MLR will still be linearly independent after the interpolation. This fact is important in the later use of the "linear" inverse model.

The values missing in bottle measurements in a section were first interpolated using bottle data from the same section. In order to check the reliability of the method, we determined differences between actually measured values and, assuming that no measurements existed at that location, values obtained by the MLR method using data from neighboring stations. Such differences have small standard deviations. In the example of silica at A09 (Fig. 2, black, lower lines in figure text), the standard deviation of the difference is $0.883 \mu \mathrm{mol}$ $\mathrm{kg}^{-1} \mathrm{SiO}_{4}$, corresponding to $0.7 \%$ of the total data range, thus being smaller than the relative measurement uncertainty of $1 \mu \mathrm{mol} \mathrm{kg} \mathrm{kg}^{-1} \mathrm{SiO}_{4}$.

In a next step, variables not measured at one section were interpolated using data from another cruise at similar locations if available (e.g., phosphate for A08 was interpolated using phosphate data from Oceanus 133, both at $11^{\circ} \mathrm{S}$ ). If data from a similar location were not 

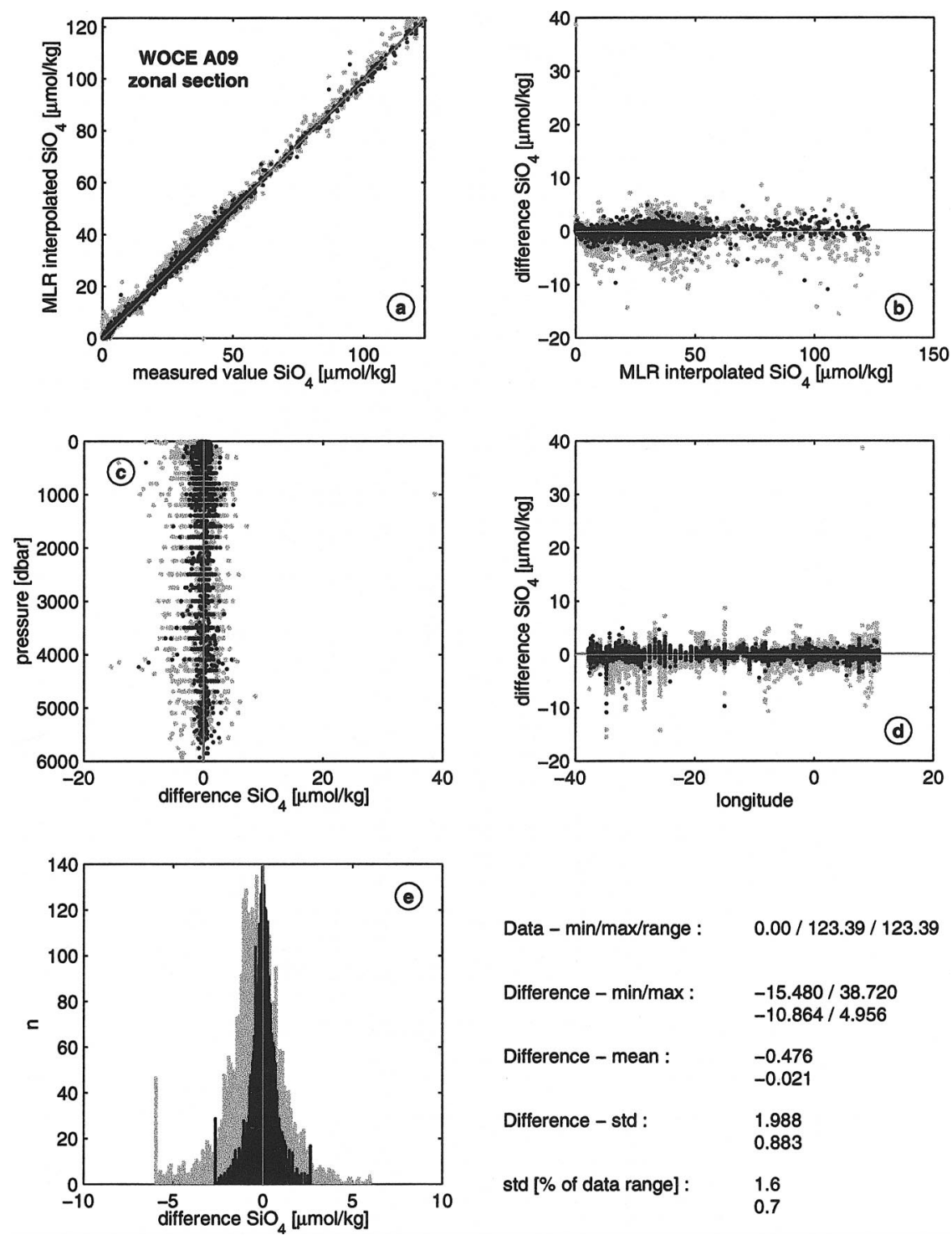

FIG. 2. An example for the difference between instrumentally measured $\mathrm{SiO}_{4}$ values and values simulated by multiple linear regression (MLR) at the same locations of the whole zonal section A09 at $19^{\circ} \mathrm{S}$ for two different cases: First, when each individual measurement was recalculated using data from neighboring stations of the A09 section only (in black). Second, when all the measured A09 silica concentrations were deleted before the MLR run, based on all other sections (in gray). (a) Correlation between measured and interpolated values, the distribution of the difference vs (b) value, (c) pressure, (d) longitude, and (e) as a histogram. In the lower right corner: the range of the measured $\mathrm{SiO}_{4}$ values in $\mu$ mol kg-1 $(\max -\min )$, the highest positive and negative difference between the measured and simulated values, the mean difference, and the standard deviation of the difference in $\mu \mathrm{mol} \mathrm{kg}^{-1}$ and in percent of the measured data range. In figure text the upper lines are for the case using all other sections, lower lines for the case using A09 only. The parameters used for this MLR calculation are given in Table 3.

available, data from all neighboring sections were used. This step provided a consistent parameter set at bottle depths on all sections.

The quality of this procedure is demonstrated by the following example (Fig. 2, gray, upper lines in figure text). All measured silica values on section A09 were removed and then simulated using the MLR with all the available sections with silica data. As to be expected, filling the gaps with data from other sections produces larger differences than filling in with data from the same section (Fig. 2, black). But the standard deviation of the differences $\left(1.988 \mu \mathrm{mol} \mathrm{kg}{ }^{-1} \mathrm{SiO}_{4}\right)$ is still smaller than double the measurement uncertainty. Also, no trend can be seen either in the horizontal or vertical or in absolute values in the fit (Figs. 2b-d). In a last step, these data were then used to map the parameters onto the CTD 


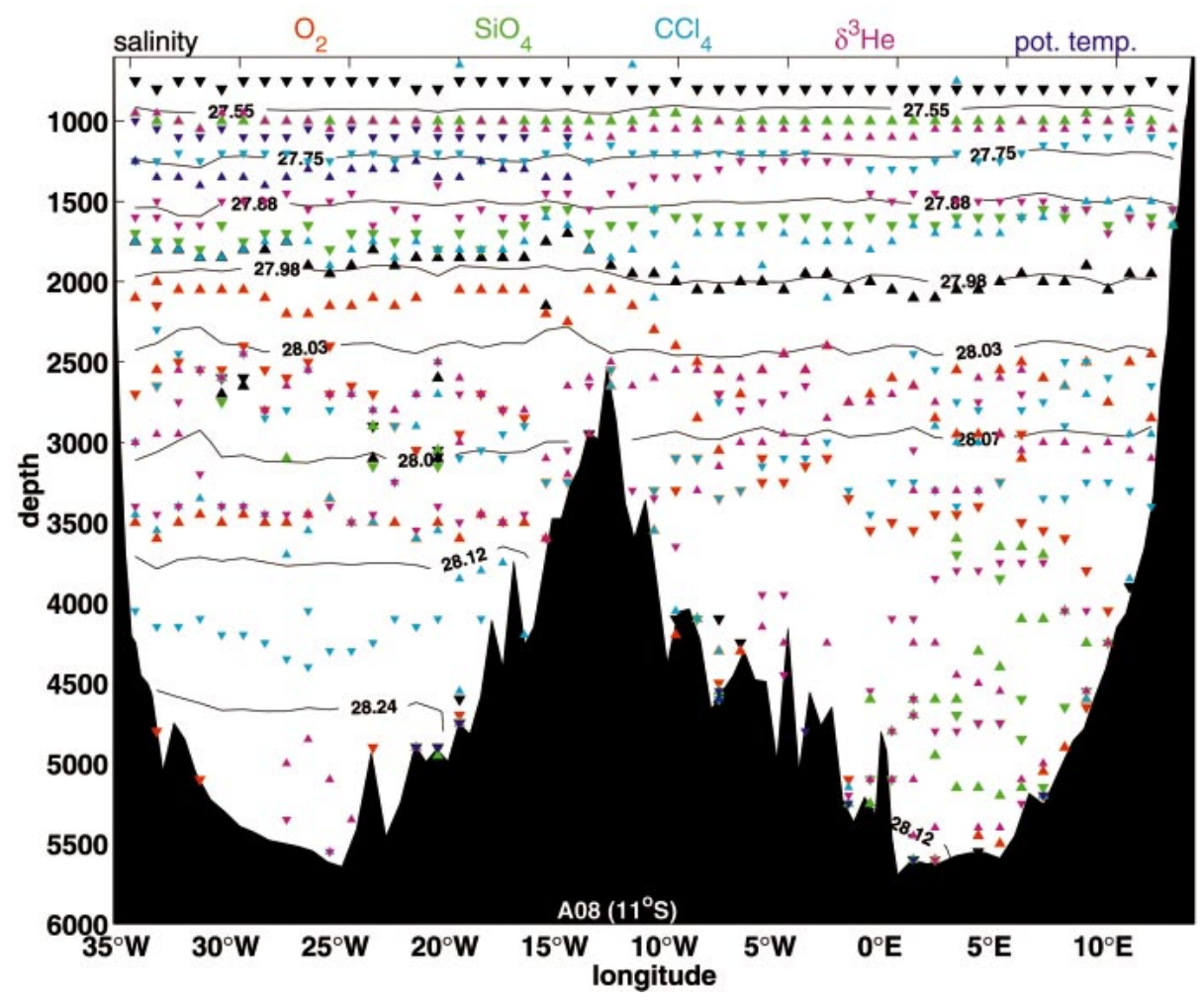

FIG. 3. Locations of the local property extrema at the zonal section A08 at $11^{\circ} \mathrm{S}: \triangle$ : maximum, $\nabla$ : minimum, black: salinity, red: oxygen, green: silica, light blue: $\mathrm{CCl}_{4}$, violet: $\delta^{3} \mathrm{He}$, dark blue: potential temperature. In the background are the isolines of neutral density $\gamma_{n}$, which served as layer boundaries in the inverse model. Depth is given in meters here and in the following figures.

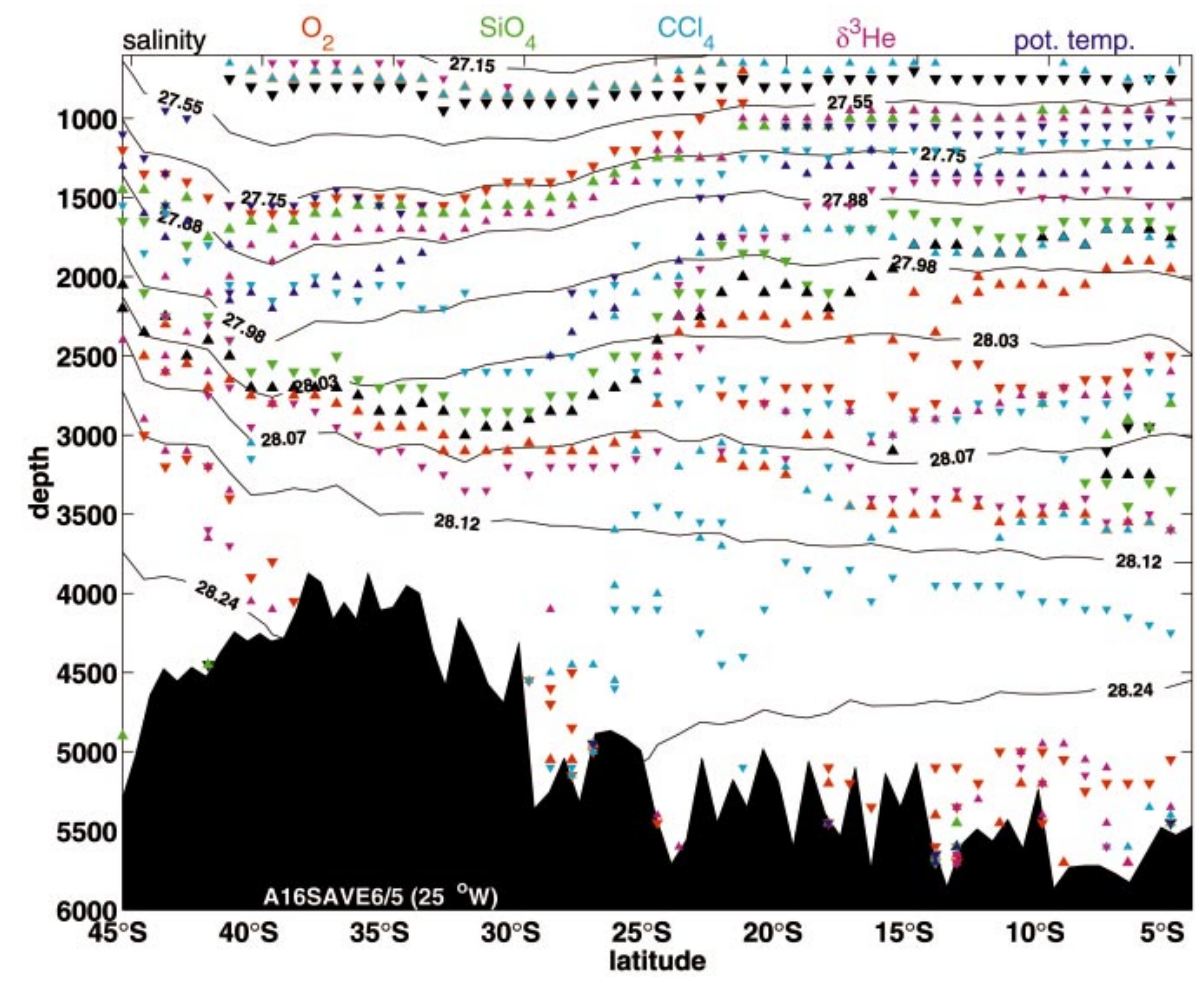




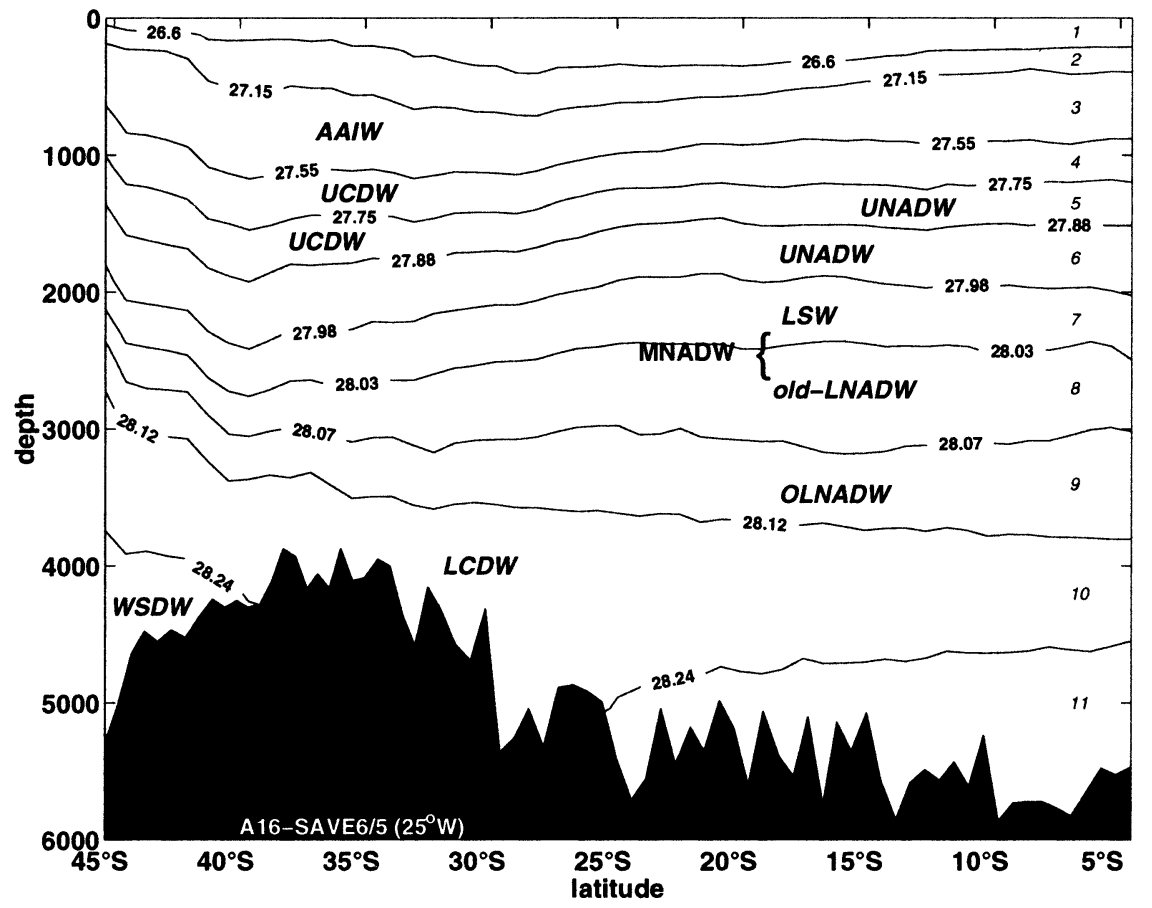

FIG. 5. Selected water masses, example for the meridional section A16 (SAVE 5/6) at $25^{\circ} \mathrm{W}$. The names indicate the major water mass in the particular layer, but other water masses may also be present. The layer numbers are near the right margin. For layer definitions see Table 4.

data, again using the MLR. The statistics shown for $\mathrm{SiO}_{4}$ (Fig. 2) are typical for the other nutrients as well (silica and phosphate were used in the constraints). The deviations are higher for anthropogenic tracers and helium due to the coarser sampling. But those were not used in the current constraint set.

\section{Inverse model}

\section{a. Method}

The deep zonal fluxes emphasized here were determined from hydrographic, nutrient, and tracer data (terrigenic helium and $\mathrm{CFCs}$ ), using a linear geostrophic box-inverse model (Wunsch 1978). We used a simple model assuming:

- geostrophic and hydrostatic balance and Ekman transport,

- steady-state ocean (with the underlying ergodic assumption),

- flow occurring in layers between neutral density surfaces,

- near-conservation for different properties (see below),

- negligible diapycnal mixing contribution to the conservation equations.
For the solution we used a truncated singular value decomposition technique (SVD) applied to row- and column-weighted equations. The unknowns are the 1039 reference velocities, and the standard model used here contains 784 equations. The effects of possible deviations from a steady state due to crossover in nonsynoptic sections are considered in the weighting of equations.

It is known from observations that diapycnal transports can play a major role in certain regions of the South Atlantic, particularly above rough topography (Polzin et al. 1997; Ledwell et al. 1999). The use of a "zero mixing model" leads to minimizing of diapycnal mixing. Nevertheless, information about the exchange across isopycnals can be found in the residuals of the inversion. Because of the minimization method, the solutions of the linear system will not be exact and some diapycnal transports will exist in the solutions.

One could incorporate diapycnal fluxes directly in the inverse model, and this might provide better estimates of the real circulation. Here we assume that the model does not require diapycnal fluxes in order to diagnose the zonal flows and choose the simpler route of obtaining the diapycnal transport as a residuum. We will later observe that the model actually does not require diapycnal fluxes to diagnose the zonal flows. 
TABLE 4. The 11 layers used in the conservation equations of the inverse model for all sections and boxes, specified by the bounding upper and lower neutral densities $\gamma_{n}$ and the corresponding water mass. The mean potential temperature in ${ }^{\circ} \mathrm{C}$ (upper value) and salinity (lower value) of each layer are shown for the nine "cross-Atlantic" zonal sections.

\begin{tabular}{|c|c|c|c|c|c|c|c|c|c|c|c|}
\hline Layer & $\gamma_{n}$ & Water mass & $\begin{array}{l}\mathrm{A} 07 \\
4.5^{\circ} \mathrm{S}\end{array}$ & $\begin{array}{c}\text { OCE } 133 \\
11^{\circ} \mathrm{S}\end{array}$ & $\begin{array}{l}\mathrm{A} 08 \\
11^{\circ} \mathrm{S}\end{array}$ & $\begin{array}{l}\text { SAVE } 2 \\
19^{\circ}-10^{\circ} \mathrm{S}\end{array}$ & $\begin{array}{l}\mathrm{A} 09 \\
19^{\circ} \mathrm{S}\end{array}$ & $\begin{array}{l}\text { OCE } 133 \\
23^{\circ} \mathrm{S}\end{array}$ & $\begin{array}{c}\text { SAVE } 3 / 4 \\
25^{\circ} \mathrm{S}\end{array}$ & $\begin{array}{l}\mathrm{A} 10 \\
30^{\circ} \mathrm{S}\end{array}$ & $\begin{array}{l}\text { A11 } \\
45^{\circ} \mathrm{S}\end{array}$ \\
\hline 1 & $\begin{array}{l}\text { Surface } \\
26.60\end{array}$ & & $\begin{array}{l}20.13 \\
35.813\end{array}$ & $\begin{array}{l}21.10 \\
36.260\end{array}$ & $\begin{array}{l}21.14 \\
36.251\end{array}$ & $\begin{array}{l}20.07 \\
36.255\end{array}$ & $\begin{array}{l}19.28 \\
36.064\end{array}$ & $\begin{array}{l}18.34 \\
35.862\end{array}$ & $\begin{array}{l}17.44 \\
35.691\end{array}$ & $\begin{array}{l}16.84 \\
35.610\end{array}$ & $\begin{array}{l}13.67 \\
34.920\end{array}$ \\
\hline 2 & $\begin{array}{l}26.60 \\
27.15\end{array}$ & & $\begin{array}{l}10.51 \\
34.983\end{array}$ & $\begin{array}{l}10.39 \\
34.980\end{array}$ & $\begin{array}{l}10.39 \\
34.974\end{array}$ & $\begin{array}{l}10.42 \\
34.951\end{array}$ & $\begin{array}{l}10.07 \\
34.857\end{array}$ & $\begin{array}{l}10.11 \\
34.855\end{array}$ & $\begin{array}{c}9.93 \\
34.815\end{array}$ & $\begin{array}{c}9.94 \\
34.815\end{array}$ & $\begin{array}{c}8.86 \\
34.623\end{array}$ \\
\hline 3 & $\begin{array}{l}27.15 \\
27.55\end{array}$ & AAIW & $\begin{array}{c}5.61 \\
34.539\end{array}$ & $\begin{array}{c}5.65 \\
34.544\end{array}$ & $\begin{array}{c}5.55 \\
34.529\end{array}$ & $\begin{array}{c}5.41 \\
34.513\end{array}$ & $\begin{array}{c}5.13 \\
34.470\end{array}$ & $\begin{array}{c}4.92 \\
34.424\end{array}$ & $\begin{array}{c}4.65 \\
34.373\end{array}$ & $\begin{array}{c}4.55 \\
34.352\end{array}$ & $\begin{array}{c}3.84 \\
34.248\end{array}$ \\
\hline 4 & $\begin{array}{l}27.55 \\
27.75\end{array}$ & UCDW & $\begin{array}{c}4.19 \\
34.651\end{array}$ & $\begin{array}{c}3.95 \\
34.612\end{array}$ & $\begin{array}{c}3.95 \\
34.613\end{array}$ & $\begin{array}{c}3.81 \\
34.590\end{array}$ & $\begin{array}{c}3.65 \\
34.566\end{array}$ & $\begin{array}{c}3.41 \\
34.532\end{array}$ & $\begin{array}{c}3.13 \\
34.488\end{array}$ & $\begin{array}{c}3.05 \\
34.475\end{array}$ & $\begin{array}{c}2.66 \\
34.415\end{array}$ \\
\hline 5 & $\begin{array}{l}27.75 \\
27.88\end{array}$ & UCDW/UNADW & $\begin{array}{c}4.15 \\
34.873\end{array}$ & $\begin{array}{c}3.85 \\
34.822\end{array}$ & $\begin{array}{c}3.87 \\
34.825\end{array}$ & $\begin{array}{c}3.74 \\
34.802\end{array}$ & $\begin{array}{c}3.62 \\
34.780\end{array}$ & $\begin{array}{c}3.24 \\
34.717\end{array}$ & $\begin{array}{c}2.95 \\
34.670\end{array}$ & $\begin{array}{c}2.86 \\
34.655\end{array}$ & $\begin{array}{c}2.57 \\
34.608\end{array}$ \\
\hline 6 & $\begin{array}{l}27.88 \\
27.98\end{array}$ & UNADW & $\begin{array}{c}3.67 \\
34.958\end{array}$ & $\begin{array}{c}3.50 \\
34.926\end{array}$ & $\begin{array}{c}3.49 \\
34.923\end{array}$ & $\begin{array}{c}3.42 \\
34.910\end{array}$ & $\begin{array}{c}3.33 \\
34.895\end{array}$ & $\begin{array}{c}3.12 \\
34.858\end{array}$ & $\begin{array}{c}2.88 \\
34.814\end{array}$ & $\begin{array}{c}2.78 \\
34.796\end{array}$ & $\begin{array}{c}2.52 \\
34.746\end{array}$ \\
\hline 7 & $\begin{array}{l}27.98 \\
28.03\end{array}$ & LSW & $\begin{array}{c}3.05 \\
34.943\end{array}$ & $\begin{array}{c}3.00 \\
34.935\end{array}$ & $\begin{array}{c}2.96 \\
34.927\end{array}$ & $\begin{array}{c}2.92 \\
34.920\end{array}$ & $\begin{array}{c}2.91 \\
34.917\end{array}$ & $\begin{array}{c}2.86 \\
34.909\end{array}$ & $\begin{array}{c}2.69 \\
34.877\end{array}$ & $\begin{array}{c}2.58 \\
34.857\end{array}$ & $\begin{array}{c}2.33 \\
34.805\end{array}$ \\
\hline 8 & $\begin{array}{l}28.03 \\
28.07\end{array}$ & old-LNADW & $\begin{array}{c}2.59 \\
34.919\end{array}$ & $\begin{array}{c}2.58 \\
34.917\end{array}$ & $\begin{array}{c}2.55 \\
34.910\end{array}$ & $\begin{array}{c}2.53 \\
34.907\end{array}$ & $\begin{array}{c}2.52 \\
34.904\end{array}$ & $\begin{array}{c}2.51 \\
34.904\end{array}$ & $\begin{array}{c}2.44 \\
34.899\end{array}$ & $\begin{array}{c}2.38 \\
34.875\end{array}$ & $\begin{array}{c}2.08 \\
34.813\end{array}$ \\
\hline 9 & $\begin{array}{l}28.07 \\
28.12\end{array}$ & OLNADW & $\begin{array}{c}2.17 \\
34.899\end{array}$ & $\begin{array}{c}2.12 \\
34.895\end{array}$ & $\begin{array}{c}2.10 \\
34.889\end{array}$ & $\begin{array}{c}2.09 \\
34.889\end{array}$ & $\begin{array}{c}2.09 \\
34.886\end{array}$ & $\begin{array}{c}2.11 \\
34.888\end{array}$ & $\begin{array}{c}2.09 \\
34.875\end{array}$ & $\begin{array}{c}2.06 \\
34.870\end{array}$ & $\begin{array}{c}1.72 \\
34.799\end{array}$ \\
\hline 10 & $\begin{array}{l}28.12 \\
28.24\end{array}$ & LCDW & $\begin{array}{c}1.28 \\
34.816\end{array}$ & $\begin{array}{c}1.20 \\
34.808\end{array}$ & $\begin{array}{c}1.11 \\
34.792\end{array}$ & $\begin{array}{c}1.08 \\
34.790\end{array}$ & $\begin{array}{c}1.07 \\
34.785\end{array}$ & $\begin{array}{c}1.18 \\
34.802\end{array}$ & $\begin{array}{c}1.08 \\
34.782\end{array}$ & $\begin{array}{c}1.06 \\
34.775\end{array}$ & $\begin{array}{c}0.86 \\
34.734\end{array}$ \\
\hline 11 & $\begin{array}{l}28.24 \\
\text { Bottom }\end{array}$ & WSDW & $\begin{array}{c}0.34 \\
34.717\end{array}$ & $\begin{array}{c}0.31 \\
34.717\end{array}$ & $\begin{array}{c}0.31 \\
34.711\end{array}$ & $\begin{array}{c}0.29 \\
34.711\end{array}$ & $\begin{array}{c}0.22 \\
34.702\end{array}$ & $\begin{array}{c}0.25 \\
34.715\end{array}$ & $\begin{array}{c}0.29 \\
34.712\end{array}$ & $\begin{array}{c}0.02 \\
34.681\end{array}$ & $\begin{array}{c}-0.54 \\
34.674\end{array}$ \\
\hline
\end{tabular}

\section{b. Water mass selection}

\section{1) Structure of water masses}

As will be discussed later, we will assume in the inverse analysis that the flow occurs in layers between neutral density surfaces (Jackett and McDougall 1997). We therefore first determined the structure of the water mass layers in detail. Similar to Peterson and Whitworth (1989), who used temperature, salinity, oxygen, and nutrients, the cores of different water masses were defined by their characteristic property extrema (Table 1). For this purpose the properties on each section were gridded (with $\Delta z=50 \mathrm{~m}$ in the vertical) and the locations of the local extrema were plotted with neutral density surfaces in the background. Figures 3 and 4 give examples for the zonal section $\mathrm{A} 08$ at $11^{\circ} \mathrm{S}$ and the meridional section $\mathrm{A} 16$ at $25^{\circ} \mathrm{W}$, with the locations of property minima and maxima.

The analysis includes more properties than are usually considered. The results on the distributions of water masses may be useful for other studies also, and we therefore give a detailed description of water masses based on this new analysis in the appendix.

\section{2) LAYERS FOR THE INVERSION}

Based on the water mass structure presented in the appendix, the water column was divided into 11 layers. The 10 neutral density surfaces that separate these layers are shown in the background of Figs. 3 and 4 and together with the names of the major enclosed water mass- es in Fig. 5. The corresponding mean values of $\theta$ and salinity of each layer for the nine "cross-Atlantic" zonal sections are shown in Table 4.

The use of neutral density surfaces instead of potential density (both are almost parallel at midlatitudes in the South Atlantic) allowed a more precise water mass separation at the southern boundary of the inversion region. Near the southern boundary of the domain the potential isopycnals are displaced vertically by as much as 500 to $1000 \mathrm{~m}$ (see Fig. 4). Since we assume that the horizontal transports occur in layers between isopycnal surfaces, it is important that water mass boundaries closely resemble isopycnal mixing surfaces. The above meridional depth changes make it difficult to select a single reference level for each boundary when using potential density, whereas the neutral density surfaces better fulfill the requirement. The incorporation of tracers provides additional information for separating water masses.

The chlorofluorocarbon (CFC, or freon) compounds CFC-11 $\left(\mathrm{CFCl}_{3}\right)$ and CFC-12 $\left(\mathrm{CF}_{2} \mathrm{Cl}_{2}\right)$ have been measured routinely since about 1980 (e.g., Weiss et al. 1985; Pickart et al. 1989; Rhein 1994), whereas measurement of CFC-113 $\left(\mathrm{CCl}_{2} \mathrm{FCClF}_{2}\right)$ (not used here) and $\mathrm{CCl}_{4}$ (CFC-10) became possible during WOCE in 1990 (Roether and Putzka 1996). The tracer $\mathrm{CCl}_{4}$ was released into the environment from the beginning of the last century, mostly by the dry cleaning industry and as a source substance for the CFC production. It is thus among the earliest of the transient tracers. Therefore it had more time to enter the deep ocean and proves to 
be a highly useful tracer for the deep layers (Roether and Putzka 1996). Especially in the NADW and bottom water layers in the South Atlantic, the $\mathrm{CCl}_{4}$ signal is stronger compared to that of the of CFC-11 or CFC-12, and can be traced farther from the ventilation regions. But in contrast to the other $\mathrm{CFCs}, \mathrm{CCl}_{4}$ is unstable near the surface. Although $\mathrm{CCl}_{4}$ is mainly of anthropogenic origin, a possible natural source was discussed by Lovelock et al. (1973).

In the Brazil Basin, the $\mathrm{CCl}_{4}$ maxima of the upper and lower NADW layers were used to define the whole NADW layer more accurately. Our layer 5 (UNADW/ UCDW; $27.75<\gamma_{n}<27.88$ ) is a transition layer between the Upper Circumpolar Deep Water (UCDW) and the Upper NADW (UNADW). It depends on latitude which water mass is carried by this layer. The decision can be made by using the additional $\mathrm{CFC}$ or $\mathrm{CCl}_{4}$ tracer information. Previous studies at $11^{\circ} \mathrm{S}$ used an upper NADW boundary at $\sigma_{2}=36.65$ (McCartney 1993), which is only about $70 \mathrm{~m}$ shallower than our upper boundary of the UNADW/UCDW layer, but positioned above the $\mathrm{CFC}$ or $\mathrm{CCl}_{4}$ minimum of the $\mathrm{UCDW}$ in the whole Brazil Basin outside the deep western boundary current (DWBC). At this latitude the $\mathrm{CCl}_{4}$ concentrations suggest the choice of a deeper level as the upper NADW boundary, and the transition layer carries water with UCDW properties. This deviation will not make a great difference in fluxes, but provides a better confidence in the selection of boundaries.

The additional use of $\delta^{3} \mathrm{He}$ makes it possible to differentiate between the $\delta^{3} \mathrm{He}$-poor NADW, $\delta^{3} \mathrm{He}$-rich CDW, and relatively $\delta^{3} \mathrm{He}$-poor Weddell Sea Deep Water (WSDW), and improves the choice of water mass boundaries. The advantage of using $\delta^{3} \mathrm{He}$ instead of $\mathrm{SiO}_{4}$ for the separation of abyssal water masses in the southern South Atlantic was documented by Rüth (1998). In contrast to the $\mathrm{SiO}_{4}$ concentration, which increases monotonically from NADW over the Lower Circumpolar Deep Water (LCDW) to WSDW and toward the bottom, decreasing $\delta^{3} \mathrm{He}$ concentrations were found below the LCDW (4500 m) in the Argentine Basin. This distribution leads to a local $\delta^{3} \mathrm{He}$ maximum in the core of the LCDW, located between the lower $\delta^{3} \mathrm{He}$ values of NADW and WSDW. Of course, how far north this water mass can be traced depends on the choice of the WSDW upper boundary, and the selection of this boundary can be improved using $\delta^{3} \mathrm{He}$.

To trace the core of bottom water with WSDW origin, we looked at the bottle data from all deep profiles for a decrease in $\delta^{3} \mathrm{He}$ near the bottom (helium was measured only on A08, A09, and A10). At $30^{\circ} \mathrm{S}$ we were able to locate such $\delta^{3} \mathrm{He}$ profiles in the Vema and Hunter Channels and in the Cape Basin. Farther north at $19^{\circ} \mathrm{S}$ (A09) and $11^{\circ} \mathrm{S}$ (A08) there still exist profiles with a $\delta^{3} \mathrm{He}$ maximum of the LCDW detached from the bottom by a layer about $100 \mathrm{~m}$ thick with a $\delta^{3} \mathrm{He}$ decrease (Fig. $6 a)$. The thickest WSDW layer with a $\delta^{3} \mathrm{He}$ decrease was found in the deep entrances to the Brazil Basin, with up to $650 \mathrm{~m}$ thickness in the Vema Channel (Fig. $6 b)$. In the extension of the Hunter Channel this layer is in a lower density range compared to the Vema Channel, reflecting the shallower sills of the Hunter Channel farther south (Fig. 6e). Although the thickness of the layer with decreasing $\delta^{3} \mathrm{He}$ is up to $500 \mathrm{~m}$ thick (Fig. $6 \mathrm{c}$ ) in the Cape Basin, the layer is nearly homogeneous in density and lighter than in the western basins (Fig. 6f).

To verify our choice for the LCDW/WSDW boundary, we have used the profile with the densest water near the entrance to the Brazil Basin (section A10, Station 11 at $30.0^{\circ} \mathrm{S}, 39.4^{\circ} \mathrm{W}$ in the Vema Channel). Although there is no significant change in the shape of the salinity, temperature, or silica profiles in the Antarctic Bottom Water (AABW) density range, both the bottle data and the MLR interpolated profile show a significant decrease in $\delta^{3} \mathrm{He}$ below $\gamma_{n}=28.24$ (Fig. 7).

\section{c. Initial reference levels}

Some of the results on water mass interfaces were also used in choosing initial reference levels for the calculation of the a priori geostrophic velocity. The selection of an initial reference level is an important part of the inverse model specification. Several previous studies, which were mostly based on hydrographic data originating from zonal sections, used numerous different choices for reference levels. In most cases the reference levels lie between two dominant water masses moving in opposite directions: in the case of the South Atlantic, between NADW and either the overlying UCDW, or Antarctic Intermediate Water (AAIW) where no UCDW exists, or between NADW and the underlying AABW. Although such a choice seems plausible, one has to look closely at certain regions, for example, the DWBC regions where both $\mathrm{AABW}$ and NADW can flow poleward (Weatherly et al. 2000).

We chose initial reference levels in a way that they represent as best as possible the present state of knowledge of the South Atlantic circulation. For the zonal sections the following choices were made (summarized in Table 5).

Section A07 $\left(4.5^{\circ} \mathrm{S}\right)$ :

The direct current measurements obtained from the moored array at $35^{\circ} \mathrm{W}$ in the equatorial passage (Hall et al. 1997) show a flow reversal at $4100 \mathrm{~m}$ at the two southernmost moorings (nearest to shore) and suggest a slightly shallower reversal to the north. This suggests the NADW/AABW interface as an appropriate choice for a reference level. Another detailed study of the equatorial region using anthropogenic tracers led Rhein et al. (1998) to select a deeper reference level at $\sigma_{4}=45.90$. But farther south at $5^{\circ} \mathrm{S}$ (west of $30.5^{\circ} \mathrm{W}$ ) they do not recommend this choice because the DWBC reaches the bottom at this latitude. 

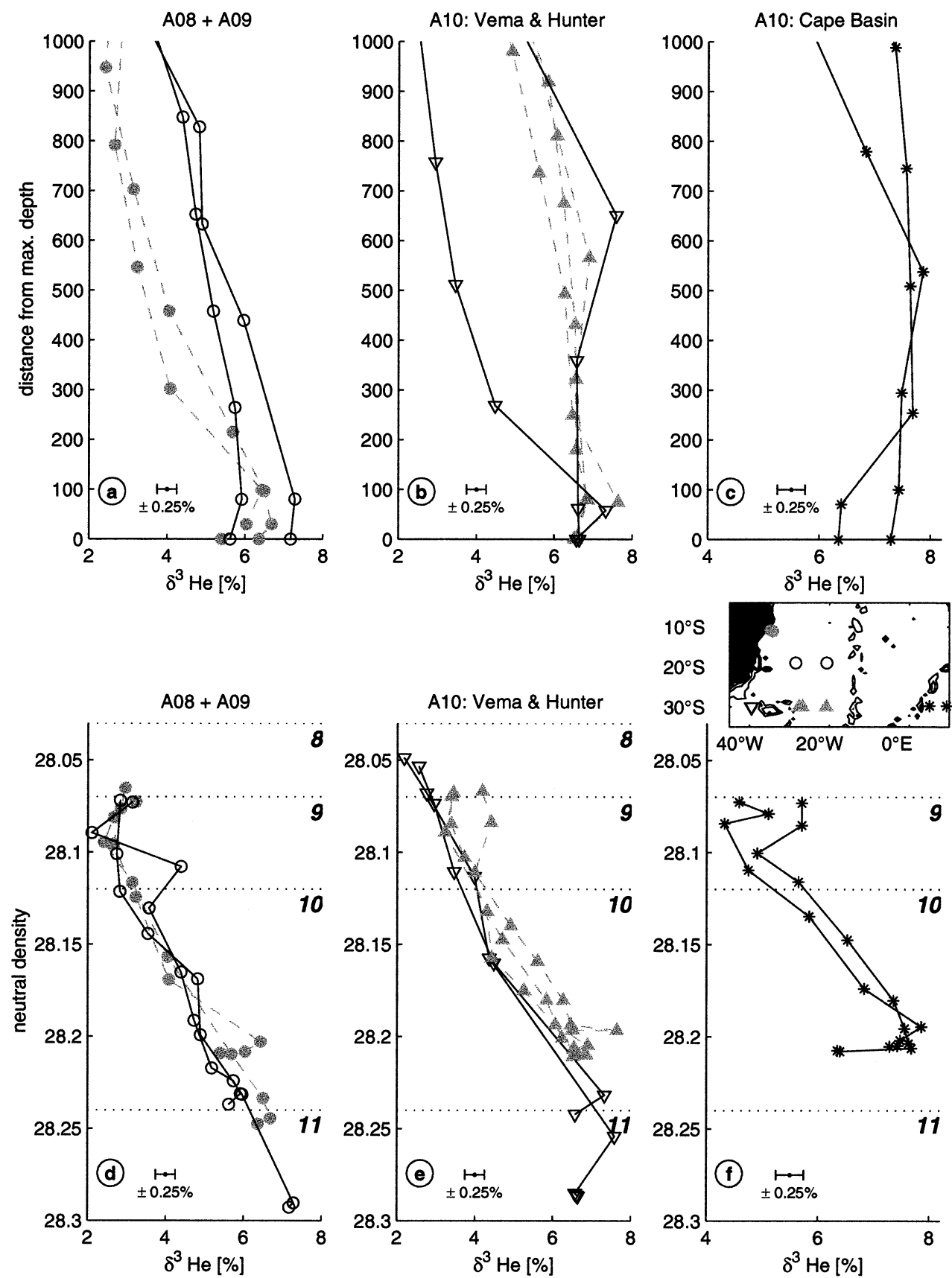

FIG. 6. Selected profiles of $\delta^{3} \mathrm{He}$ from bottles showing the thickness of the layer with decreasing $\delta^{3} \mathrm{He}$ near the bottom $(\mathrm{a}-\mathrm{c})$ vs distance from the deepest measurement and vs $(\mathrm{d}-\mathrm{f})$ neutral density over our choice of deep-layer boundaries (dotted line). The location of the profiles is shown in the map. Open circle: A08, solid circle: A09, $\nabla$ : Vema Channel, $\triangle$ : Hunter Channel, asterisk: Cape Basin. The standard $\delta^{3} \mathrm{He}$ data precision (derived from duplicates) ranges from $0.20 \%$ (Roether and Putzka 1996; Roether et al. 1998) to 0.25\% (Rüth et al. 2000). A corresponding error bar is located near the lower left corner of each panel.

We therefore placed the reference level at the bottom in the western part (west of $30^{\circ} \mathrm{W}$ ) of $\mathrm{A} 07$ and at the NADW/AABW interface with $\gamma_{n}=28.135$ at approximately $3900 \mathrm{~m}$ in the remaining Brazil Ba$\sin \left(30^{\circ}-16^{\circ} \mathrm{W}\right)$. In the Guinea and Angola Basins we followed Warren and Speer (1991) for $11^{\circ} \mathrm{S}$, with a reference level at $2400 \mathrm{~m}$ above the MAR and at $4000 \mathrm{~m}$ within the basin (Table 5).

Section A11 $\left(45^{\circ} \mathrm{S}\right)$ :

For this southernmost section of our dataset Saunders and King (1995) used a reference level at $\sigma_{4}=$ 45.95 (equivalent to $\sigma_{3}=41.58$ ). They argued that 


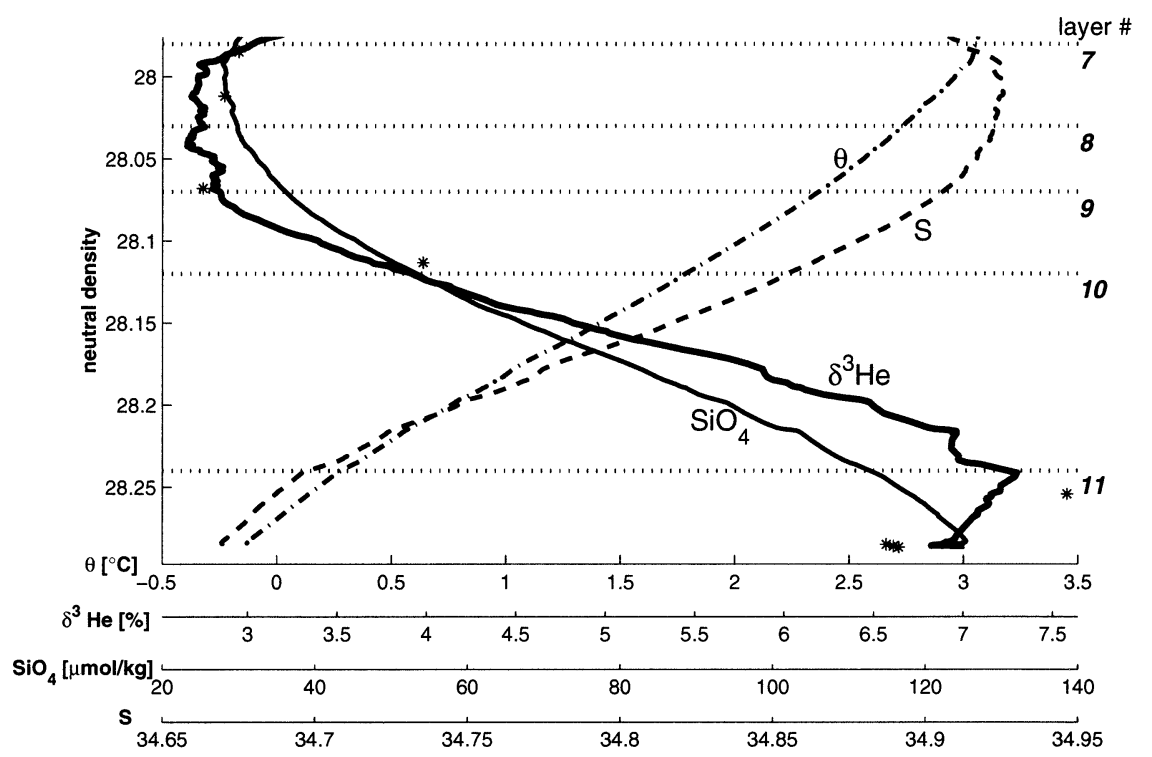

FIg. 7. Salinity $S$, potential temperature $\theta$, silica $\mathrm{SiO}_{4}$, and $\delta^{3} \mathrm{He}$ profiles in the deep Vema Channel (Station 11 at $30.0^{\circ} \mathrm{S}, 39.4^{\circ} \mathrm{W}$ in section A10). Silica and $\delta^{3} \mathrm{He}$ profiles are interpolated with MLR (see text). The stars represent $\delta^{3} \mathrm{He}$ values obtained directly from the bottle dataset (the corresponding error is $0.2 \%-0.25 \%$, see Fig. 6) and are shown to demonstrate the deviation of the "interpolated" $\delta^{3} \mathrm{He}$ profile from the "measured" one, in particular the near-bottom layer. The layer numbers are given near the right margin. For layer definitions see Table 4.

this choice yields a near-zero net mass flux across the section. We followed their choice for the entire Cape Basin and thus deviated here from the use of neutral density surfaces for the initial reference level. This density surface is found at about $4000 \mathrm{~m}$, below the high-oxygen, high-salinity, and low-nutrient water mass that originates mostly from the NADW (Fig. 8). But west of the MAR in the Argentine Basin this water mass is at a much shallower depth, at approximately $2500 \mathrm{~m}$. A reference level at $\sigma_{3}=41.58$ would be placed too deep in the core of CDW there, as seen from the lower oxygen/silica ratios in Fig. 8a. A more appropriate choice, which is similar to the selection for the Cape Basin, is a level just below the core of the NADW-influenced water mass with high oxygen and salt and low nutrient concentrations, near $\gamma_{n}$ $=28.10$.

Correspondingly we kept the choice of Saunders and King (1995) only in the Cape Basin, using a reference level at $\sigma_{3}=41.58$, which corresponds to a neutral density surface of $\gamma_{n}=28.178$. For the western part of the A11 section crossing the Argentine Basin we adjusted their choice to $\gamma_{n}=28.10$, thus ensuring that we follow similar water mass properties on both sides of the MAR (see Fig. 8).

Other zonal sections $\left(10^{\circ}-30^{\circ} \mathrm{S}\right)$ :

A detailed study on different reference level choices was presented by Holfort and Siedler (2001). We used their standard choices, which are given in Table 5. The table also contains the reference levels used by Warren and Speer (1991) at $11^{\circ} \mathrm{S}$, with
$4000 \mathrm{~m}$ in the Angola Basin and $2400 \mathrm{~m}$ above the MAR, respectively. We use these values for the corresponding longitudes of zonal sections north of $15^{\circ} \mathrm{S}$. For the eastern basin parts of zonal sections between $15^{\circ}$ and $33^{\circ} \mathrm{S} \sigma_{2}$ levels were chosen close, but slightly deeper (in approximately 1600 $\mathrm{m}$ for $\mathrm{A} 09,1550 \mathrm{~m}$ for Oceanus $23^{\circ} \mathrm{S}$, and 1850 $\mathrm{m}$ for A10) than the $1300 \mathrm{~m}$ used by Warren and Speer (1991) at $24^{\circ} \mathrm{S}$.

Meridional sections:

Because of the less complete knowledge of zonal large-scale fluxes in the South Atlantic, the selection of reference levels for meridional sections is not as straightforward. Usually we cannot assume that water masses with opposing meridional flow directions will also have opposing zonal flow directions. However, some evidence of opposite flow of NADW and AABW can be found in the displacements of deep and abyssal RAFOS floats, particularly at $25^{\circ} \mathrm{S}$ in the Brazil Basin (Hogg and Owens 1999; Hogg 2001). The major part of the floats at the NADW level were displaced eastward between $20^{\circ} \mathrm{S}$ and $25^{\circ} \mathrm{S}$, while the abyssal floats showed weak AABW motion. On the other hand, this region is also close to the westward flowing subtropical gyre return current between $25^{\circ}$ and $30^{\circ} \mathrm{S}$, according to float measurements in the AAIW layer (Boebel et al. 1999; Schmid et al. 2000). For this reason the NADW/AAIW interface will also be a reasonable choice for an initial reference level at these latitudes in the Brazil Basin. Unfortunately, there are no deep or abyssal float measurements in 
TABLE 5. Definition of the initial reference levels used in the inverse model for zonal sections as a function of latitude and longitude. At the latitude range $10^{\circ}-33^{\circ} \mathrm{S}$ the levels are similar to those of Holfort and Siedler (2001). The choice for the last latitudal segment near $45^{\circ} \mathrm{S}$ was applied for A11 and the diagonal leg of AJAX section only.

\begin{tabular}{|c|c|c|}
\hline Latitude & Longitude & Reference level \\
\hline $0^{\circ}-10^{\circ} \mathrm{S}$ & $\begin{array}{r}10.0^{\circ} \mathrm{W}-20.0^{\circ} \mathrm{E} \\
16.0^{\circ}-10.0^{\circ} \mathrm{W} \\
30.0^{\circ}-16.0^{\circ} \mathrm{W} \\
90.0^{\circ}-30.0^{\circ} \mathrm{W}\end{array}$ & $\begin{array}{l}4000 \mathrm{dbar} \\
2400 \mathrm{dbar} \\
\gamma_{n}=28.135 \\
\text { Bottom }\end{array}$ \\
\hline $10^{\circ}-15^{\circ} \mathrm{S}$ & $\begin{array}{r}10.2^{\circ} \mathrm{W}-15.0^{\circ} \mathrm{E} \\
16.2^{\circ}-10.2^{\circ} \mathrm{W} \\
35.2^{\circ}-16.2^{\circ} \mathrm{W} \\
40.0^{\circ}-35.2^{\circ} \mathrm{W}\end{array}$ & $\begin{array}{l}4000 \text { dbar } \\
2400 \text { dbar } \\
\gamma_{n}=28.135 \\
\text { Bottom }\end{array}$ \\
\hline $15^{\circ}-21^{\circ} \mathrm{S}$ & $\begin{array}{c}17.0^{\circ} \mathrm{W}-20.0^{\circ} \mathrm{E} \\
18.0^{\circ}-17.0^{\circ} \mathrm{W} \\
29.5^{\circ}-18.0^{\circ} \mathrm{W} \\
32.0^{\circ}-29.5^{\circ} \mathrm{W} \\
60.0^{\circ}-32.0^{\circ} \mathrm{W}\end{array}$ & $\begin{array}{l}\sigma_{2}=36.85 \\
\sigma_{2}=36.70 \\
4450 \mathrm{dbar} \\
4200 \mathrm{dbar} \\
\text { Bottom }\end{array}$ \\
\hline $21^{\circ}-25^{\circ} \mathrm{S}$ & $\begin{array}{c}5.0^{\circ} \mathrm{W}-20.0^{\circ} \mathrm{E} \\
16.0^{\circ}-5.0^{\circ} \mathrm{W} \\
33.0^{\circ}-16.0^{\circ} \mathrm{W} \\
34.0^{\circ}-33.0^{\circ} \mathrm{W} \\
35.0^{\circ}-34.0^{\circ} \mathrm{W} \\
36.0-35.0^{\circ} \mathrm{W} \\
37.0^{\circ}-36.0^{\circ} \mathrm{W} \\
40.0^{\circ}-37.0^{\circ} \mathrm{W} \\
60.0^{\circ}-40.0^{\circ} \mathrm{W}\end{array}$ & $\begin{array}{l}\sigma_{2}=36.84 \\
\sigma_{2}=36.86 \\
4300 \mathrm{dbar} \\
4050 \mathrm{dbar} \\
3920 \mathrm{dbar} \\
3880 \mathrm{dbar} \\
3820 \mathrm{dbar} \\
3220 \mathrm{dbar} \\
1400 \mathrm{dbar}\end{array}$ \\
\hline $25^{\circ}-33^{\circ} \mathrm{S}$ & $\begin{array}{r}14.0^{\circ} \mathrm{W}-20.0^{\circ} \mathrm{E} \\
30.0^{\circ}-14.0^{\circ} \mathrm{W} \\
37.5^{\circ}-30.0^{\circ} \mathrm{W} \\
43.5^{\circ}-37.5^{\circ} \mathrm{W} \\
60.0^{\circ}-43.5^{\circ} \mathrm{W}\end{array}$ & $\begin{array}{l}\sigma_{2}=36.90 \\
\sigma_{4}=45.94 \\
\sigma_{2}=36.90 \\
\sigma_{4}=45.94 \\
\sigma_{2}=36.90\end{array}$ \\
\hline $\begin{array}{l}45^{\circ} \mathrm{S} \\
(\mathrm{A} 11, \mathrm{AJAX})\end{array}$ & $\begin{array}{l}15.0^{\circ} \mathrm{W}-30.0^{\circ} \mathrm{E} \\
70.0^{\circ}-15.0^{\circ} \mathrm{W}\end{array}$ & $\begin{array}{l}\gamma_{n}=28.10 \\
\sigma_{3}=41.58\end{array}$ \\
\hline
\end{tabular}

the other basins, and there is no other evidence for opposite flow away from this narrow latitude band in the western South Atlantic. De Madron and Weatherly (1994) used a reference level near the NADW/AABW boundary at $\sigma_{4}=45.87$ for the meridional section A 16 along $25^{\circ} \mathrm{W}$. Correspondingly, we used a deep initial reference level near the NADW/AABW interface at $\gamma_{n}=28.135$ in the northern Brazil Basin and at $\gamma_{n}=28.10$ in the Guinea and Angola Basins. In the southern South Atlantic we chose a level at the bottom in the Argentine and Cape Basins (Fig. 9).

\section{d. Ekman transport}

For the calculation of the Ekman mass transport component normal to the ship track (calculated for each station pair) we use the annual-mean wind stress data from Hellerman and Rosenstein (1983). Although Ekman mass transport does not depend on the thickness of the Ekman layer, the Ekman flux of other properties does. To calculate the corresponding property flux we multiply the Ekman mass transport by the vertical mean of the property concentration over the upper $50 \mathrm{~m}$ at each station. Sensitivity tests using a weighted mean (after Hall and Bryden 1982) revealed that the difference in the flux due to the different schemes for calculating the Ekman layer concentrations is negligible (e.g., 0.001 PW difference for a meridional heat transport through a whole zonal section) compared to the errors arising from the wind stress data.

Within the area of our study $\left(4.5^{\circ}-45^{\circ} \mathrm{S}\right)$, the highest value for the meridional Ekman transport (regardless of the direction) occurs near the equator, with a maximum through the zonal section $\mathrm{A} 07$ at $4.5^{\circ} \mathrm{S}$ (first row in Table 6). An overview of meridional Ekman mass transports through the various zonal sections in the South Atlantic, as estimated in previous studies is given in the following rows of Table 6. The minimum of Ekman transport at $30^{\circ} \mathrm{S}$ with values $<1 \mathrm{~Sv}\left(\mathrm{~Sv} \equiv 10^{6} \mathrm{~m}^{3} \mathrm{~s}^{-1}\right)$ and the increase toward the equator is again obvious. Although the changes in values from section to section are generally continual south of $15^{\circ} \mathrm{S}$, there are large differences between some estimates for the two northern sections at $4.5^{\circ} \mathrm{S}(\mathrm{A} 07) 11^{\circ} \mathrm{S}$ (Oceanus 133). Unfortunately, in the Tropics one is confronted with the problem of the high seasonal variability and the generally higher variance of the wind field.

The importance of the time variability of the wind field for the Ekman transport was already described for the $11^{\circ} \mathrm{S}$ section (Speer et al. 1996; Oceanus 133). After Marin and Gouriou (2000) and F. Marin (2000, personal communication) there are also problems near the coastlines, due to wind stress differences between sea and land. To test the influence of different timeand space scales, we calculated the meridional Ekman transport from the ERS $1^{\circ}$-grid zonal wind stress data along the $4.5^{\circ} \mathrm{S}$ lat (approximately along the A07 section). To simulate the impact of the coastline we modified the start and end points of the zonal section by $\pm 1^{\circ}$ or $\pm 2^{\circ}$ (columns $6-8$ in Table 7 ). The maximal difference was about $2 \mathrm{~Sv}$ in each time period. Much higher is the impact of the different time periods used for the averaging of the wind stress data (different rows of Table 7). The maximal difference here is higher than $6 \mathrm{~Sv}$, and therefore more important than the "coastline" problem. It is interesting that the January 1993 values $(11.26 \mathrm{~Sv})$ are smaller, not only compared with the annual mean $(17.79 \mathrm{~Sv})$ but even with the January climatological mean (14.79 Sv). This anomaly of January 1993 explains the minimum Ekman transport values of Table 6, where synoptic data corresponding with the A07 time period were used (rows: Marin and Gouriou 2000; Lux et al. 2001). On the other hand, for the same time periods used for the averaging, the difference between estimates due to different climatologies is smaller than the impact of different time periods. So our annual mean for A07 based on Hellerman and Rosenstein (1983) differs only by about $1 \mathrm{~Sv}$ from the estimate based on ERS data $(17.79 \mathrm{~Sv})$.

Tests using general circulation models (GCMs) showed that variations in Ekman mass flux are almost instantaneously compensated by a barotropic return 

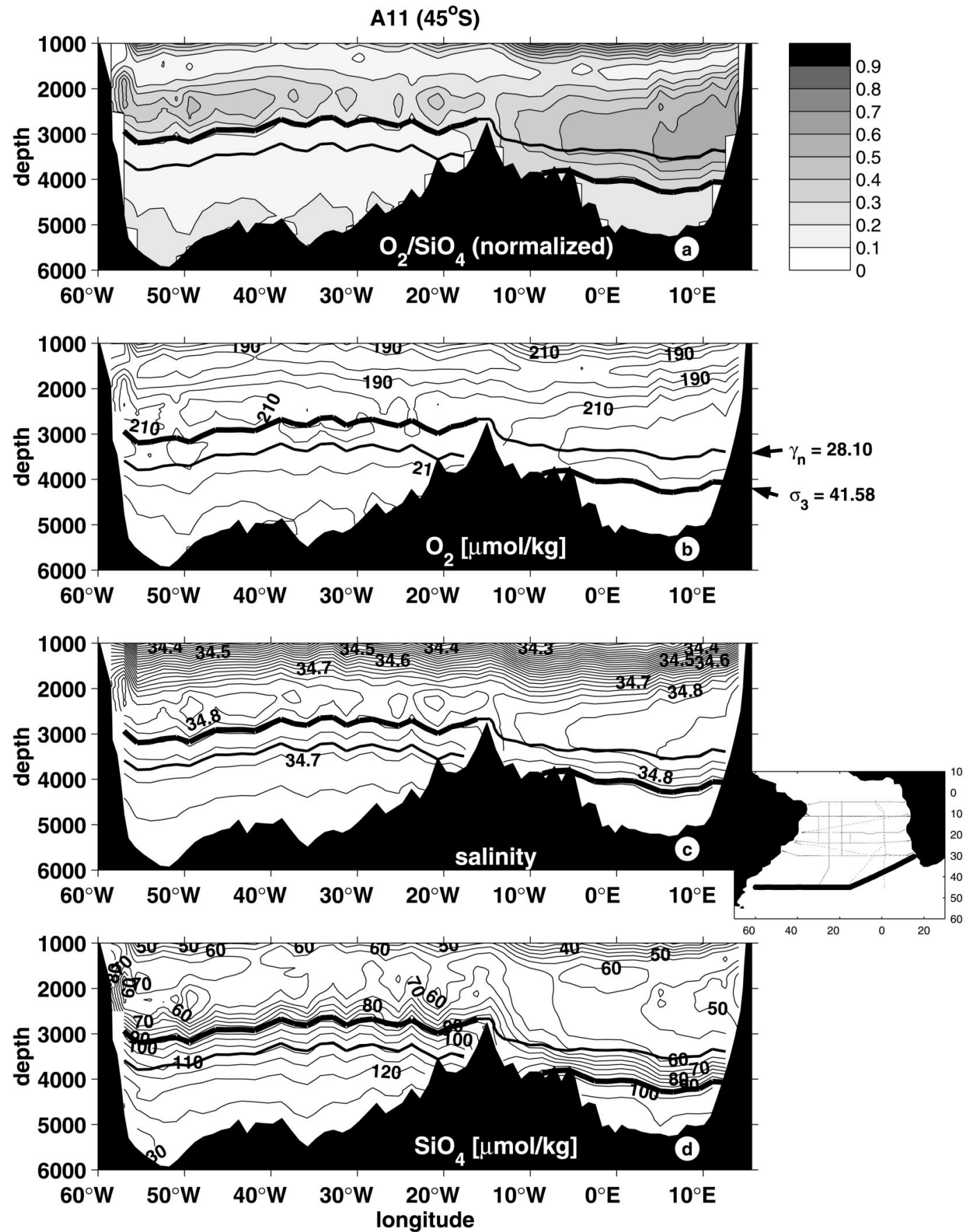

FIG. 8. (a) Normalized oxygen/silica ratio, (b) oxygen, (c) salinity, and (d) silica on the meridional section A11 at $45^{\circ} \mathrm{W}$. Higher ratio values (darker shading) in the depth range 2000-4000 $\mathrm{m}$ represent younger NADW (oxygen rich and nutrient poor); lower values (lighter shading) denote older deep water with CDW signature. The deeper thick line $\left(\sigma_{3}=41.58\right)$ was used by Saunders and King (1995) as reference level for entire section A11; the shallower one is $\gamma_{n}=28.10$. The thickest part of each was used in our calculation.

flow (Ganachaud 2001, manuscript submitted to $J$. Atmos. Oceanic Technol.; Böning and Herrmann 1994). This fast barotropic response is not important for an inverse-model study where one is interested in a "mean" solution. The baroclinic response to the wind is believed to be slow at scales of approximately 10 years (P. Robbins 2000, personal communication). For the combination of nonsynoptic sections in a steadystate calculation, as done here, it is important to use annual mean wind stress instead of synoptic data. 

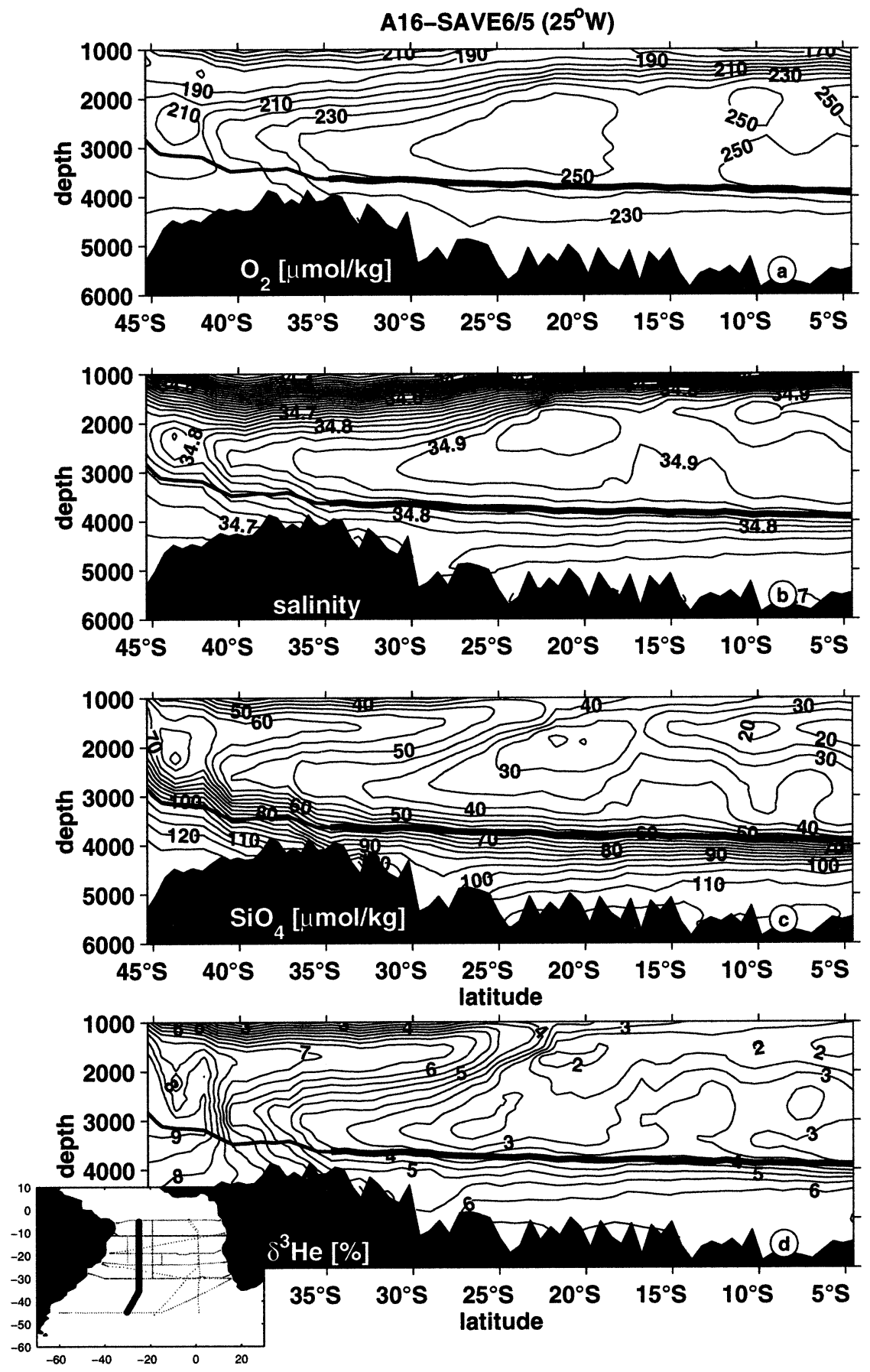

FIG. 9. Meridional distribution of oxygen, salinity, silica, and $\delta^{3} \mathrm{He}$ on the meridional section A16 at $25^{\circ} \mathrm{W}$. The thick line is $\gamma_{n}=28.135$ and the thickest part of it denotes the reference level used for all meridional sections in the Brazil Basin. South of $35^{\circ} \mathrm{S}$, in the Argentine Basin, the reference level was set to the bottom.

\section{e. Constraints}

The constraints used for the inverse model are summarized in Table 8 . It is assumed that the meridional net salt flux in the Atlantic is constant and equals the salt transport through Bering Strait, which is given by the annual mean volume transport of $0.8 \pm 0.6 \mathrm{~Sv}$ and a mean salinity of 32.5 psu (Coachman and Aagaard 1988). In contrast to some previous inversions, we use overall salt conservation that holds between every pair of density surfaces, resulting in one equation per layer in each box. Like salt, silica can be expected to be a 


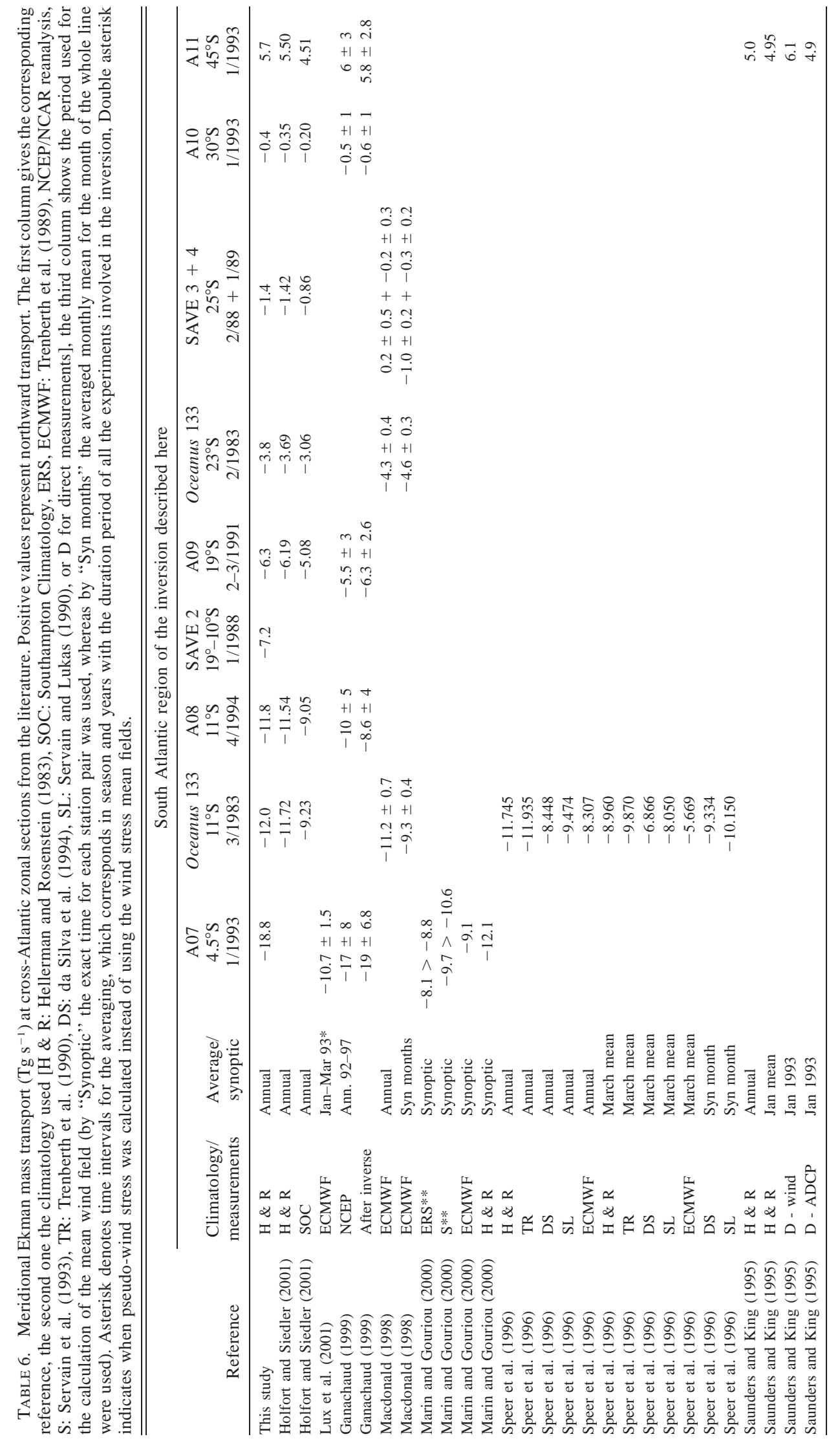


conservative property to a good approximation below the euphotic zone. A discussion on silica conservation in layers in the case of the South Atlantic was given by Holfort and Siedler (2001), and such constraints were already used in recent inversions (Macdonald 1993, 1998; Wienders et al. 2000; Holfort and Siedler 2001; Lux et al. 2001). Other authors (Robbins and Toole 1997; Ganachaud et al. 2000), however, in considering the biogeochemical cycle of silica (see Tréguer et al. 1995), suggested top-to-bottom constraints on dissolved silica in order to keep the recycling process within the box. A quantitative justification was given by Ganachaud (1999, chap. 4.3.1). In this study we use a combination of both, constraining the net (top-tobottom) silica transport as well as the transport in separate deep layers. In either case only continent-to-continent boxes are used, in contrast to salt constraints which were used in small boxes as well. To account for the possible source through dissolution in deep layers, the silica constraints were weighted relatively lower than the salt constraints of the same box.

Similar to the southward net salt flux, we prescribed a southward transport of inorganic phosphate through all sections, roughly accounting for the total phosphate transport including organic phosphorus. A net southward meridional flux of inorganic phosphate of $4 \mathrm{kmol}$ $\mathrm{s}^{-1}$ was prescribed for each zonal section (see Holfort et al. 1998; Holfort and Siedler 2001).

Constraints for volume transports inferred from direct current observations are listed in the middle part of Table 8 . We prescribed a southward Brazil Current transport of $10 \mathrm{~Sv}$ in the upper $600 \mathrm{~m}$ through the area of the 15 westernmost stations of $\mathrm{A} 10$ at $30^{\circ} \mathrm{S}$ (Holfort and Siedler 2001). A mean northward Benguela Current transport of $14 \mathrm{~Sv}$ was used for the upper 1000 $\mathrm{m}$ between the Walvis Ridge and Africa (Garzoli et al. 1997). The flow of the AABW from the Argentine Basin to the Brazil Basin (west of the MAR) was set to $7 \mathrm{~Sv}$, where $4 \mathrm{~Sv}$ of these 7 have to pass to the west of the Rio Grande Plateau, through the Vema Channel, and over the lower Santos Plateau (Hogg et al. 1999; Zenk et al. 1999).

The northward flow of AABW out of the Brazil Basin was set to $3.1 \mathrm{~Sv}$ through an abyssal layer with temperatures below $1.9^{\circ} \mathrm{C}$ for the northernmost section A07 at $4.5^{\circ} \mathrm{S}$ west of the MAR. This corresponds to the sum of the direct measurements in the north, in the equatorial passage at approximately $35^{\circ} \mathrm{W}$ (Hall et al. 1997; Rhein et al. 1998), and in the Romanche and Chain Fracture Zones (Mercier and Morin 1997). Additional constraints as given by Saunders and King (1995) were prescribed at the southernmost section A11.

Finally topographic constraints limit the flow of deep and bottom water blocked by ridges, in particular the MAR and the Walvis Ridge. Especially in the eastern basins the exchange of bottom water between the Angola and Cape Basins is assumed to be negligible below 
TABLE 8. The conservation equations used. The vertical range is given in the second column (t: integrated top-to-bottom; 1 : constraints for separate layers, all or $*$ : below the euphotic zone, $\gamma_{\mathrm{n}}>26.6$ ). The third column gives the horizontal range of the constraints (section or part of it, boxes; main: only large continent-to-continent boxes, bounded by two zonal sections, secondary: small boxes bounded by zonal and meridional sections). The scaling factors, used in the secondary scaling step, give the relative weight on the constraints (multiplicator for diagonal of the noise covariance matrix: smaller values-smaller error-higher importance of the constraint).

\begin{tabular}{|c|c|c|c|c|}
\hline Constraint & Vertical range & Horizontal range & Prescribed value & Scaling factor \\
\hline \multicolumn{5}{|c|}{ General conservation constraints } \\
\hline Southward meridional salt flux & $\mathrm{t}$ & Zonal sections & $-26.7 \times 10^{6} \mathrm{~kg} \mathrm{~s}^{-1}$ & 0.1 \\
\hline Salt conservation & 1 and $\mathrm{t}$ & Main boxes & 0 & $0.15(0.10)$ \\
\hline Salt conservation & 1 and $\mathrm{t}$ & Secondary boxes & 0 & 1.0 \\
\hline Southward meridional phosphate flux & $\mathrm{t}$ & Zonal sections & $-4 \mathrm{kmol} \mathrm{s}^{-1}$ & 0.1 \\
\hline Silica conservation & $1^{*}$ and $\mathrm{t}$ & Main boxes & 0 & $0.25(0.20)$ \\
\hline \multicolumn{5}{|c|}{ Direct measurement constraints } \\
\hline Brazil Current $\left(30^{\circ} \mathrm{S}-\mathrm{A} 10\right)$ & $0-600 \mathrm{dbar}$ & West $43.5^{\circ} \mathrm{W}$ & $-10 \mathrm{~Sv}$ & 0.02 \\
\hline Benguela Current $\left(30^{\circ} \mathrm{S}-\mathrm{A} 10\right)$ & $0-1000 \mathrm{dbar}$ & East WVR & $14 \mathrm{~Sv}$ & 0.02 \\
\hline AABW $\left(30^{\circ} \mathrm{S}-\mathrm{A} 10\right)$ & AABW & West MAR & $7 \mathrm{~Sv}$ & 0.005 \\
\hline $\mathrm{AABW}\left(30^{\circ} \mathrm{S}-\mathrm{A} 10\right)$ & AABW & Vema Channel & $4 \mathrm{~Sv}$ & 0.02 \\
\hline $\mathrm{AABW}\left(4.5^{\circ} \mathrm{S}-\mathrm{A} 07\right)$ & $\theta<1.9^{\circ} \mathrm{C}$ & West MAR & $3.1 \mathrm{~Sv}$ & 0.005 \\
\hline \multicolumn{5}{|c|}{ Constraints at A11 after Saunders and King (1995) } \\
\hline WBC & $\mathrm{t}$ & sta $12247-52$ & $45 \mathrm{~Sv}$ & 0.02 \\
\hline EBC & $t(z<2500 \mathrm{~m})$ & sta $12327-32$ & $-5 \mathrm{~Sv}$ & 0.02 \\
\hline Zapiola Anticylone (western branch) & $\mathrm{t}$ & sta $12265-70$ & $-80 \mathrm{~Sv}$ & 1.5 \\
\hline Zapiola Anticylone (eastern branch) & $\mathrm{t}$ & sta $12275-79$ & $80 \mathrm{~Sv}$ & 1.5 \\
\hline Topographic c. for Cape Basin & $\gamma_{n}>28.178$ & Cape Basin & $0 \mathrm{~Sv}$ & 0.15 \\
\hline \multicolumn{5}{|c|}{ Topographic constraints } \\
\hline Net meridional abyssal mass flux & $\gamma_{n}>28.11$ & Angola Basin & $0 \mathrm{~Sv}$ & $0.05-0.15$ \\
\hline Net meridional abyssal mass flux & $\gamma_{n}>28.11$ & Cap Basin & $0 \mathrm{~Sv}$ & $0.05-0.15$ \\
\hline No AABW mass flux over MAR & $\gamma_{n}>28.12$ & boxes over MAR & $0 \mathrm{~Sv}$ & $0.05-0.15$ \\
\hline
\end{tabular}

the sill depths of the Walvis Ridge. Therefore we prescribe zero net mass flux below $\gamma_{n}=28.11$ (corresponds approximately to $\sigma_{3}=41.521$ or $\left.\sigma_{4}=45.864\right)$ through the eastern parts of all zonal sections, separately for the Angola and Cape Basins (lower part of Table 8). In the Angola Basin the neutral surface 28.11 is warmer and in the Cape Basin colder than $\theta=2{ }^{\circ} \mathrm{C}$. Similarly the MAR is a barrier for the abyssal exchange between western and eastern basins. The major known pathways for AABW flowing across MAR are the Romanche and Chain Fracture Zones (Mercier and Morin

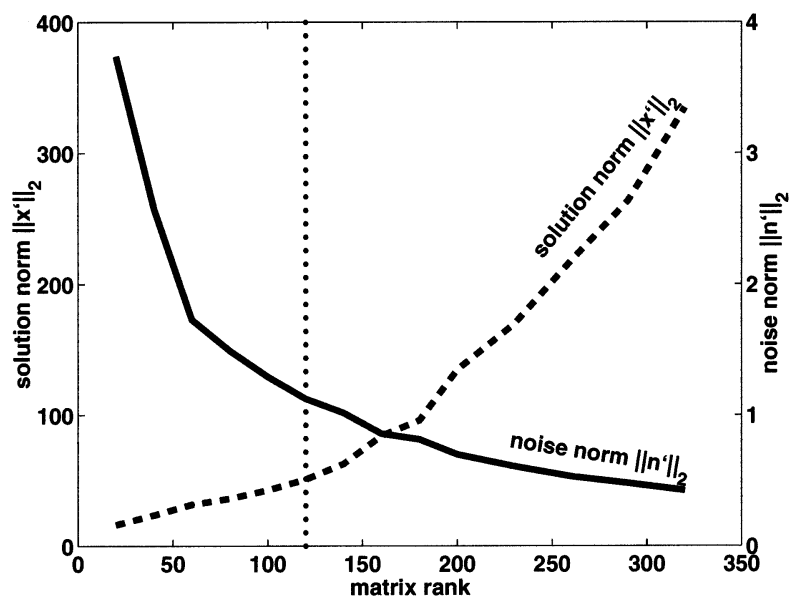

FIG. 10. The L2-norms of the residuals (solid line) and of the solutions (dashed line) as a function of matrix rank. Both $\mathrm{x}$ and $\mathrm{n}$ are from the scaled space. The rank of 120 (dotted line) was chosen.
1997) to the north of our domain near the equator. We therefore assume no exchange of $\mathrm{AABW}$ across the MAR, north of $30^{\circ} \mathrm{S}$ and south of $4.5^{\circ} \mathrm{S}$. We split all secondary boxes containing the MAR between the lines A07 and A10, prescribing a separate conservation equation below $\gamma_{n}>28.12$ on each side of the MAR. There is, however, evidence for leakage of AABW through the Rio de Janeiro Fracture Zone. According to geostrophic calculations using sections on both sides of the MAR, Mercier et al. (2000) find about $0.5 \mathrm{~Sv}$ of bottom water (below $3200 \mathrm{~m}$ ) crossing the MAR at this place. Detailed measurements in the area have shown that the density of the deepest water passing through this fracture zone is approximately at $\sigma_{4}=$ 45.87 (Ledwell et al. 2000). Our "closing of MAR" below $\gamma_{n}>28.12$ corresponds to about $\sigma_{4}=45.88$ and is therefore in accordance to the recent Rio de Janeiro depth measurements.

\section{f. Weights, scaling, and rank}

All these constraints were used to set up a system of linear equations for the unknown reference-level velocity component. The inversion minimizes the residuals (noise) and the deviation from an initial state, using the truncated SVD applied to row- and columnweighted equations. An important feature of the least squares (and SVD) is that least squares is a curve fitting procedure (a deterministic process) and not a statistical estimator (as the Gauss-Markov method is). In curve fitting, one is free to pick whatever weights/scales one 

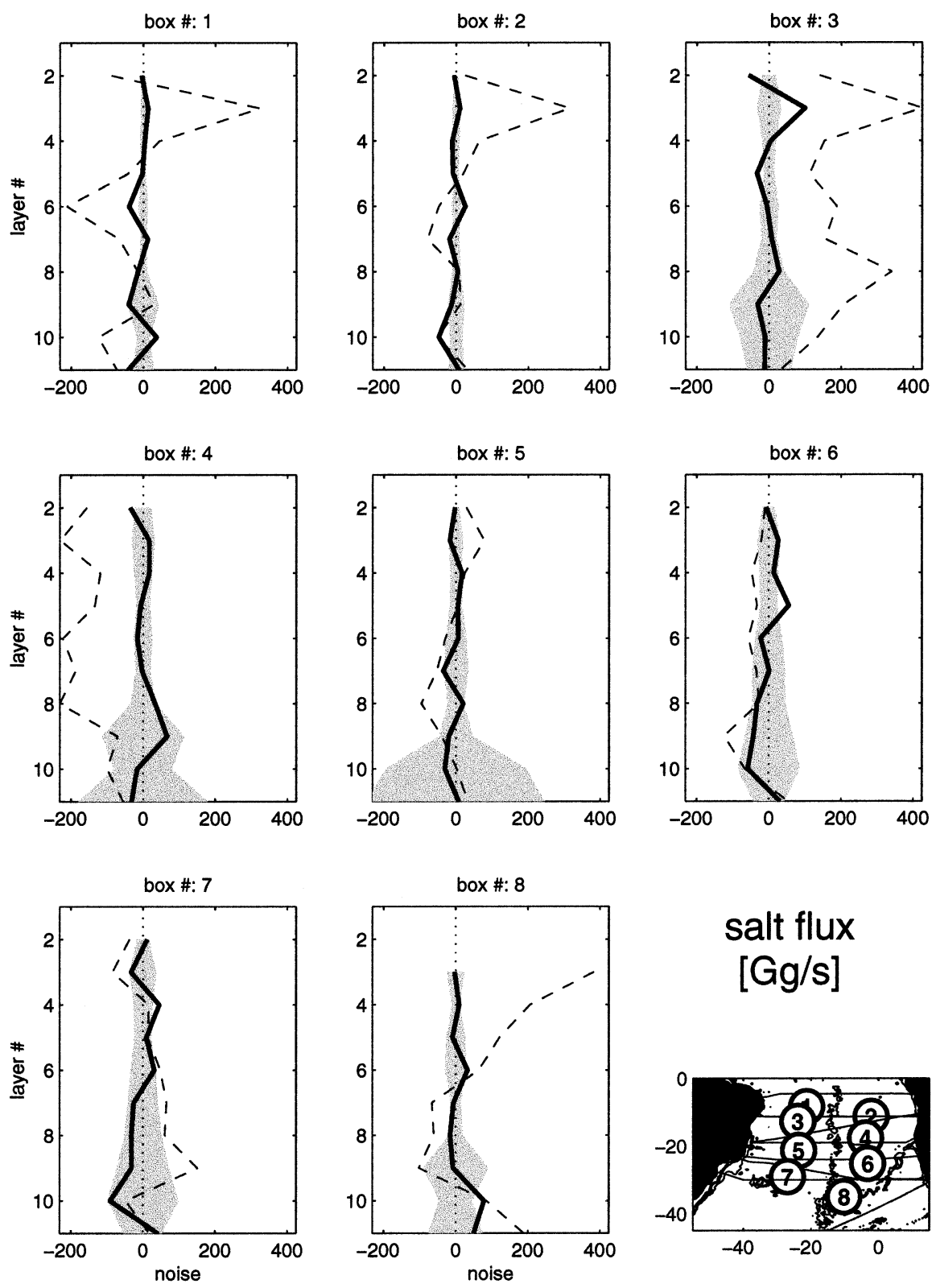

\section{salt flux $[\mathrm{Gg} / \mathrm{s}]$}

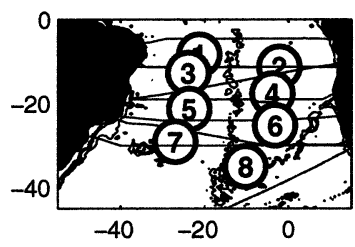

FIG. 11. Noise (residuals in $\mathrm{Gg} \mathrm{s}^{-1}=10^{6} \mathrm{~kg} \mathrm{~s}^{-1}$ ) of salt conservation in layers for all eight "main" (continent-to-continent) boxes. The boxes are ordered from north to south and their geographical location is shown in the lower right panel. Dashed lines show the a priori residuals, resulting from the initial state, before the inversion was applied. Thick, solid lines and the shaded areas show the a posteriori noise and the corresponding a posteriori uncertainty on it using the rank 120. Most, but not all of the a posteriori residuals are indistiguishable from zero within the a posteriori error bars.

seeks. It does not necessarily lead to a minimum variance estimate, but one can still estimate the uncertainty owing to noise, failure to resolve, etc. Though the choice of the weighting matrices is free here, there are some "preferred" common strategies (e.g., expected a priori (co)variance for noise and solution, weights to produce the smoothest solution, etc.). In our geostrophic inversion, since we know so little about the statistics of the flow or noise, we tried not to use "unknown" covariances in the scaling directly, but rather indirectly in two steps. In the first step all elements (numerical values of the matrix coefficients) would come out to be nearly identical in magnitude. Then we applied a second (relative) scaling, introducing a priori estimates of how big the solution values (for column scaling) or the "relative" errors in the equations (for row scaling) should be. The latest was realized by multiplying each diagonal element of the 

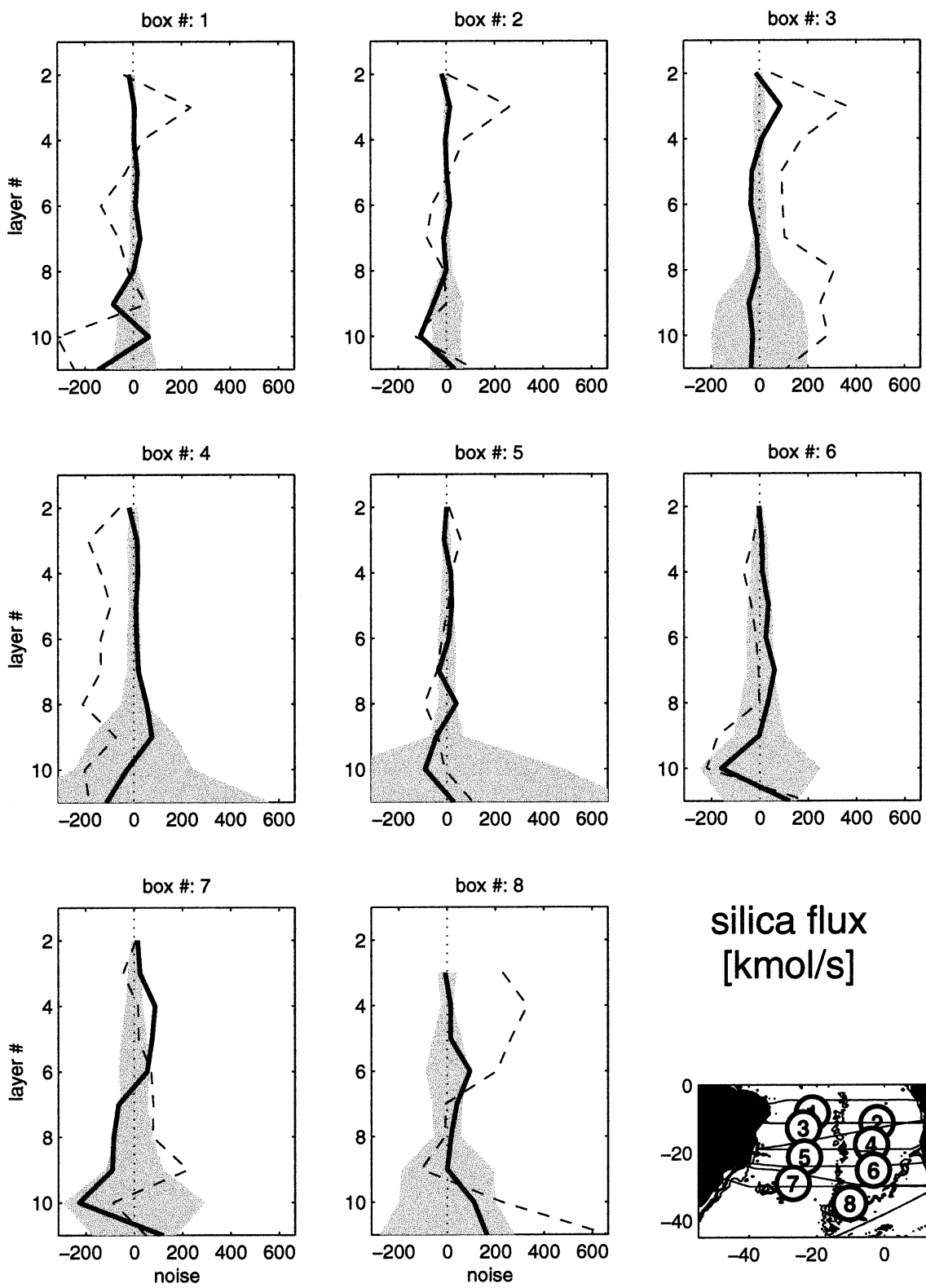

\section{silica flux $[\mathrm{kmol} / \mathrm{s}]$}

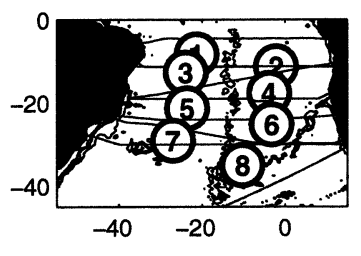

FIG. 12. As in Fig. 11 but for noise (residuals in $\mathrm{kmol} \mathrm{s}^{-1}$ ) of the silica conservation in layers for all eight main boxes.

scaling matrix resulting from the first step with a relative weighting factor. No off-diagonal terms were used in this inversion.

Because the a priori covariances were not chosen to play the role of the weighting matrices directly, the a priori uncertainties do not affect the solution vector and a posteriori noise. But, off course, they do affect the a posteriori errors (uncertainty) on both. Our estimates for the a priori uncertainties for the property conservation constraints are based on the assumed mass transport error $\left\langle n_{M}\right\rangle=2 \times 10^{-9} \mathrm{~kg} \mathrm{~s}^{-1}$ scaled with the tracer variation in the box and the measurement accuracies:

$$
\begin{aligned}
\left\langle n_{C}^{2}\right\rangle= & \left\langle n_{M}^{2}\right\rangle \\
& \times\left(\left\langle\Delta C_{\text {sides }}^{2}\right\rangle+\left\langle\Delta C_{\text {tower }}^{2}\right\rangle+\left\langle\Delta C_{\text {upper }}^{2}\right\rangle+\left\langle C_{\text {acc }}^{2}\right),\right.
\end{aligned}
$$

where $\Delta C_{\text {sides }}, \Delta C_{\text {lower }}, \Delta C_{\text {upper }}$ are the standard deviations of the tracer concentration around the box, and on the upper and lower boundary of the layer, and $C_{\text {acc }}$ the measurement accuracies. The a priori uncertainties for the direct measurement constraints are based on the reported error on the mean.

Weights were applied to the equations (which correspond to the rows of matrices) first on the basis of the magnitudes of their coefficients (i.e., scaled with the maximum absolute values). The secondary scaling 

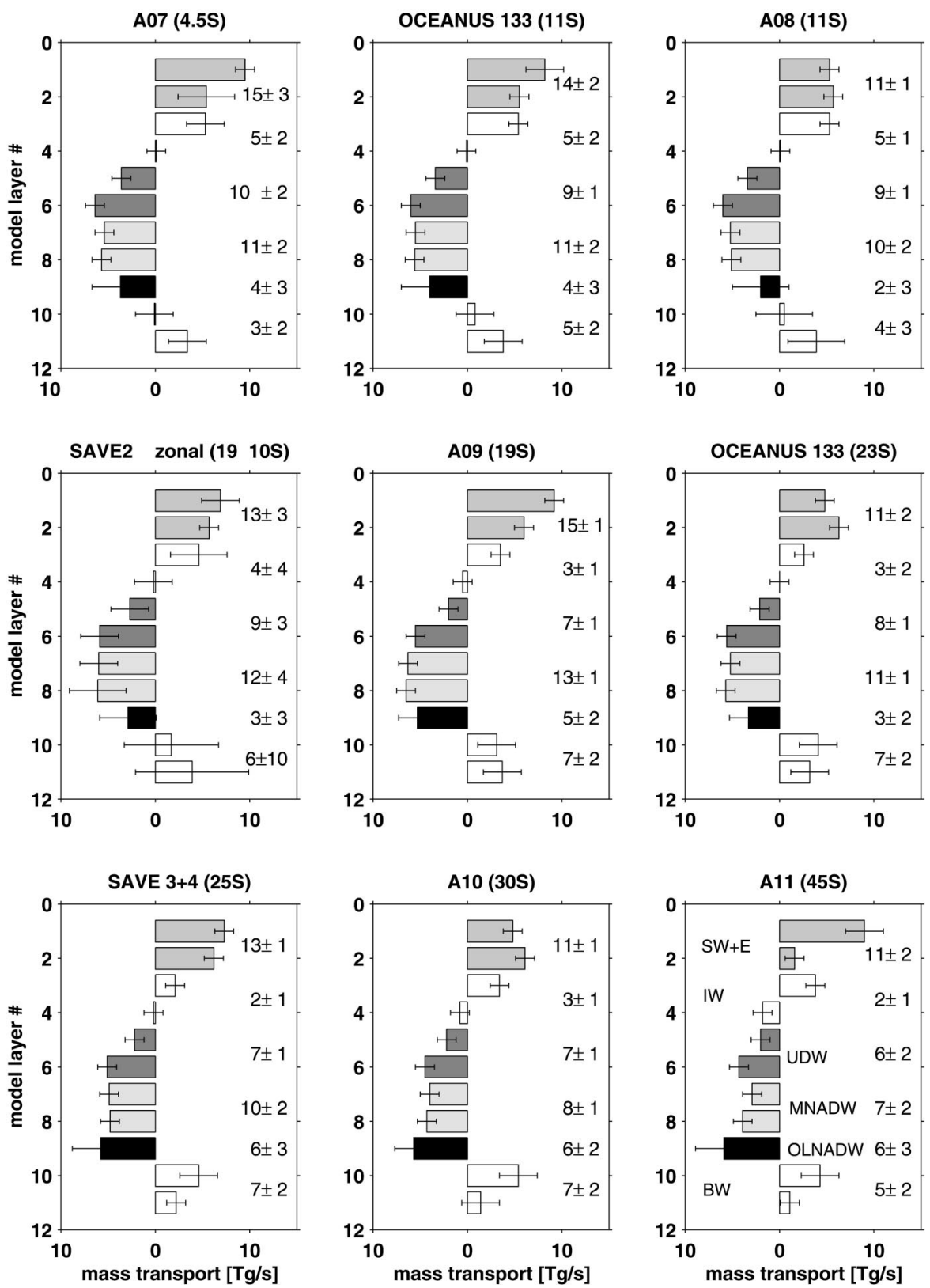

FIG. 13. Vertical distribution of the meridional mass transport $\left(\mathrm{Tg} \mathrm{s}^{-1}\right)$ on the nine "cross-Atlantic" zonal sections (values correspond nearly to those of transport in Sv). Positive transports are northward. The error bars show the $95 \%$ confidence interval for each layer. The total amounts carried by each water mass and the corresponding uncertainty (separated by different shading) are on the right hand side of each box: Surface water with Ekman transport (SF+E), AAIW/UCDW (IW); UCDW/UNADW (UDW); LSW, LNADW-old (MNADW); OLNADW; LCDW, WSDW (BW). For layer definitions see Table 4.

factors for equations, based on an a priori estimate of the relative uncertainty in the constraints, are listed in the Table 8. Constraints based on direct observations are given the highest priority. In box conservation equations we generally assume a smaller error for the conservation in the main (cross-Atlantic) boxes than in the secondary boxes. The larger error in the secondary boxes is to be expected because of the problem of matching nonsynoptic meridional and zonal sections. A smaller error compared to the other main boxes is expected in the special case of a main box, which was defined by the pair of repeat sections at $11^{\circ} \mathrm{S}$ (A08 and Oceanus 133 sections, values in parenthesis in Table 8), where the part of the residual imbalance due to the neglected diapycnal transfer is minimized. 


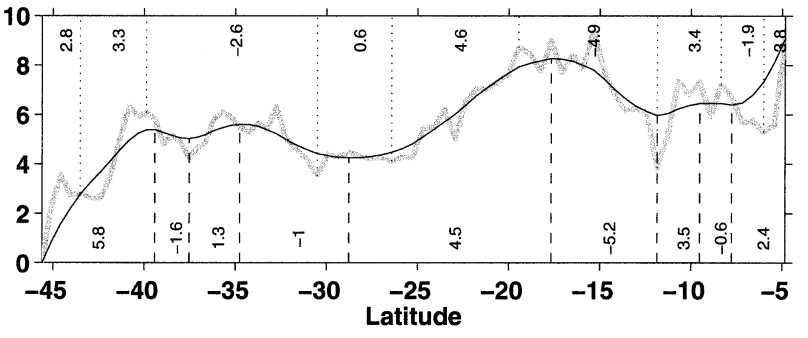

FIG. 14. Mass transport in the MNADW layer (7-8) of the meridional section $\mathrm{A} 16$ at $25^{\circ} \mathrm{W}$ (thick gray line), cumulated from the south, in $10^{9} \mathrm{~kg} \mathrm{~s}^{-1}$, positive to the east. Thin black line shows the transport after zero-phase digital filtering. Dashed vertical lines (in the lower part of the figure) denote locations, where the derivate of the filtered transport is zero. This first-order separation of different flow regimes was then adjusted manually (dotted vertical lines). Such adjusted separation limits were estimated for each section and layer and used in Figs. 15 and 19. The enclosed numbers correspond to the net transport (of the original data) in each band. In both versions, in the "objective-first order" and in the "adjusted" version, the dominating features in the cumulated transport are the eastward fluxes south of $40^{\circ} \mathrm{S}$ and around $22.5^{\circ} \mathrm{S}$

The confidence in the unknown reference-level velocities was expressed by the weighting of the columns in the model matrix. In the first step we scaled by the total area of the corresponding station pair. Additionally, older sections with larger station spacing (SAVE 1-4) were downweighted in the second step with a factor of 3 .

The matrix rank has a great influence on the transport calculation. Our typical inverse system has about 995 unknowns and 765 equations, and solutions were calculated up to rank 400. The higher the rank, the more exactly the equations are solved (decreasing noise norm $\left\|n^{\prime}\right\|_{2}$ in Fig. 10), but the larger are the deviations from the initial state (increasing solution norm $\left\|x^{\prime}\right\|_{2}$ in Fig. 10). Figure 10 demonstrates this trade-off between the a posteriori noise and solution size. Because it is in the rotated and scaled space, it does not show the magnitudes in the dimensional space (in physical units). At high ranks (over 320) the solutions give unreasonably large reference-level velocities with mean $>7 \mathrm{~cm} \mathrm{~s}^{-1}$, median $>1.8 \mathrm{~cm} \mathrm{~s}^{-1}$, and maximum $=40 \mathrm{~cm} \mathrm{~s}^{-1}$. The particular solution chosen is for rank 120. This is the smallest rank for which most of the equations are satisfied within their uncertainties. For example, Figs. 11 and 12 show the reduction of the a priori residuals (dashed lines) of the salt and silica conservation to much lower a posteriori values (thick, solid line) using rank 120. The majority of the a posteriori residuals are indistinguishable from zero within the a posteriori error bars (Figs. 11 and 12 shaded) at this rank. In this way the obtained solution is the smallest one (with $v_{\text {ref }}$ mean $=2.6 \mathrm{~cm} \mathrm{~s}^{-1}$, median $=0.25 \mathrm{~cm} \mathrm{~s}^{-1}$, and the small $\left\|x^{\prime}\right\|_{2}$ in Fig. 10) that satisfies the constraints.

\section{g. Solution uncertainty}

The uncertainty $P_{\tilde{x} \tilde{x}}$ of the estimated minimal solution $\tilde{x}$ corresponds to the dispersion of $\tilde{x}$ about the true value $x$. Both the a priori solution (parameter) error and the a priori noise (residual) error (the covariance matrixes $R_{x x}$ and $R_{n n}$ ) contribute to the solution uncertainty:

$$
\begin{aligned}
P_{\tilde{x} \tilde{x}} & \equiv\left\langle(\tilde{x}-x)(\tilde{x}-x)^{\mathrm{T}}\right\rangle \\
& =\left(T_{v}-I\right) R_{x x}\left(T_{v}-I\right)^{\mathrm{T}}+\underbrace{B R_{n n} B^{\mathrm{T}}}_{C_{\tilde{x} \tilde{x}}},
\end{aligned}
$$

where $B$ is the generalized inverse, used for the calculation of the solution vector estimates $(\tilde{x}=B y)$. Only in the case of "perfect" solution resolution, where the solution resolution matrix $T_{v}$ equals the identity matrix $I$, would there be no contribution from the a priori solution error and the uncertainty matrix $P_{\tilde{x} \tilde{x}}$ would equal he solution covariance $C_{\tilde{x} \tilde{x}} \equiv\left\langle(\tilde{x}-\langle\tilde{x}\rangle)(\tilde{x}-\langle\tilde{x}\rangle)^{\mathrm{T}}\right\rangle$.

In our case using the SVD for a particular rank $K$, the expression for the solution uncertainty (in the rotated and scaled space) can be expressed as

$$
\begin{aligned}
P_{\tilde{x} \tilde{x}}= & \frac{\left(V_{K} V_{K}^{\mathrm{T}}-I\right) R_{x x}\left(V_{K} V_{K}^{\mathrm{T}}-I\right)^{\mathrm{T}}}{T_{v}} \\
& +\frac{\underbrace{}_{B}}{V_{K} \Lambda_{K}^{-1} U_{K}^{\mathrm{T}}} R_{n n} U_{K} \Lambda_{K}^{-1} V_{K}^{\mathrm{T}},
\end{aligned}
$$

where $\Lambda_{K}$ is the reduced diagonal matrix of singular values $\lambda_{i}$ and $V_{K}$ is the matrix of first $K$ singular vectors $v_{i}$.

It is the uncertainty matrix $P_{\tilde{x} \tilde{x}}$ that is used to calculate the a posteriori flux errors shown in Figs. 15 and 19. These formal errors represent a lower bound on the true error, as they do not include the error that arises from the missing null space vector contribution and represent the error on the reference-level velocities themselves.

\section{Net meridional transports}

In Fig. 13 we show how the model did its job regarding the meridional overturning. In each panel we present the vertical distribution of the net meridional mass transport $\left(\mathrm{Tg} \mathrm{s}^{-1}\right)$ through the zonal sections crossing the South Atlantic from coast to coast, ordered from north (A07) to south (A11). The northward flux of surface, intermediate, and bottom water is compensated by a southward flux of deep water at all sections. The strength of the meridional overturning cell amounts to $25 \mathrm{Tg} \mathrm{s}^{-1}$ in the north and $19 \mathrm{Tg} \mathrm{s}^{-1}$ in the south.

With the prescribed constraints the total AABW transport decreases from $6.8 \mathrm{Tg} \mathrm{s}^{-1}$ at $30^{\circ} \mathrm{S}$ to $3.4 \mathrm{Tg}$ $\mathrm{s}^{-1}$ at $4.5^{\circ} \mathrm{S}$. This requires a diapycnal upwelling of about $3.5 \mathrm{~Sv}$ AABW into the NADW layers in the Brazil Basin. An unrealistic result of this model run is the transport structure in the AABW sublayers. In the region of the narrow Vema Channel the WOCE standard horizontal resolution might be too low to resolve 

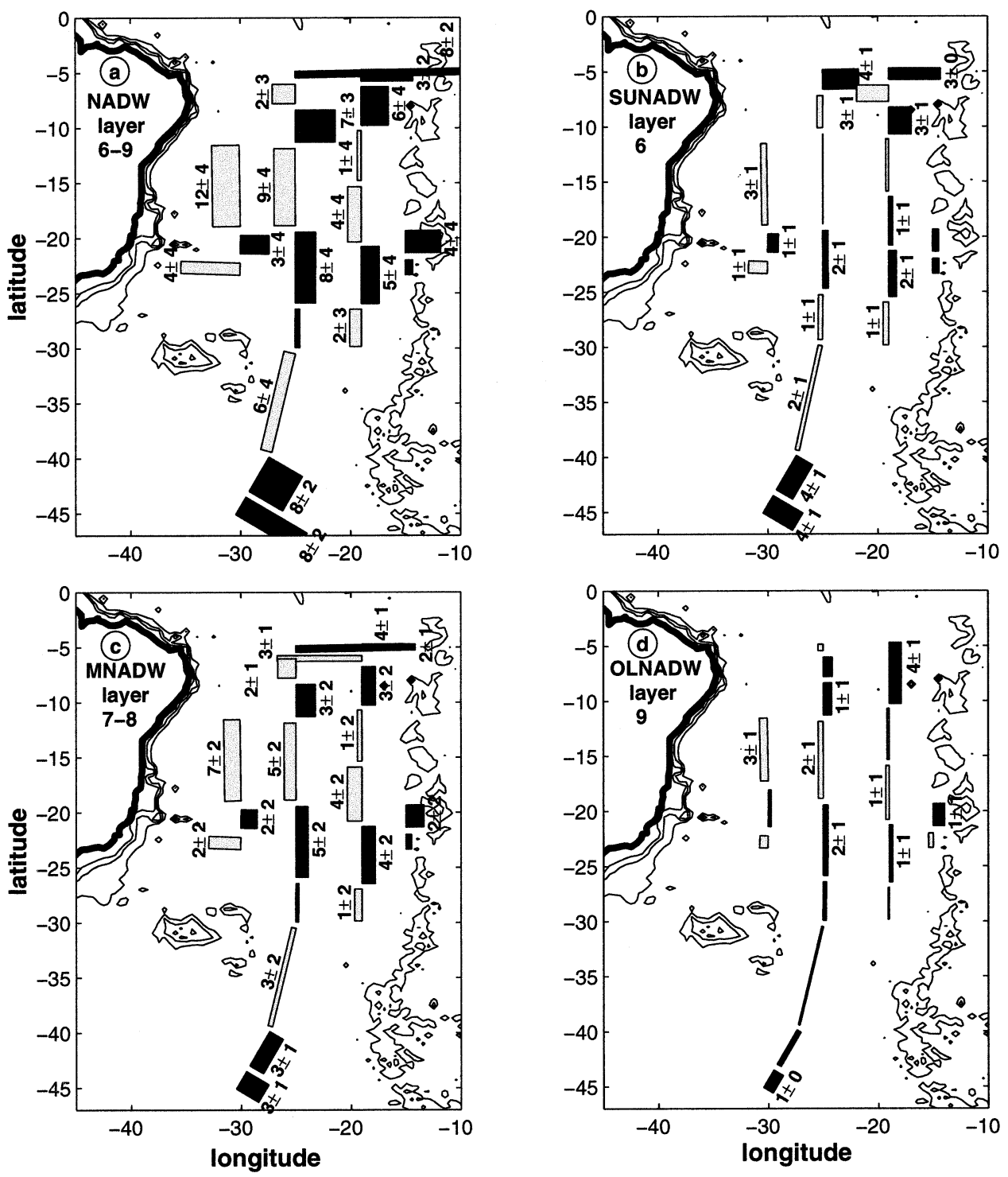

FIG. 15. Zonal transport and the corresponding uncertainty $\left(\operatorname{Tg~s}^{-1}\right)$ (a) in NADW: layers 6-9, (b) UNADW: layer 6, (c) MNADW: layers 7-8, and (d) OLNADW: layer 9, divided into separate bands that dominate the spreading directions for the meridional sections: Oceanus 133 at $30^{\circ} \mathrm{W}, \mathrm{A} 16$ at $25^{\circ} \mathrm{W}, \mathrm{A} 15$ at $19^{\circ} \mathrm{W}$, and A09 (meridional part) at $15^{\circ} \mathrm{W}$. Eastward transports are black, westward ones are gray. Transport values are rounded to whole numbers and printed on the side of the bar, which is in the direction of flow. The layers are defined by neutral density surfaces given in Table 4 .

the transport structure of the WSDW [see also description in section $3 \mathrm{~b}(2)]$. To maintain the prescribed constraints for the whole AABW layer the model produced a northward increasing flux of the denser AABW component, the WSDW. A sensitivity run using constraints for a common layer of the whole AABW (only 1 layer below $\gamma_{n} \geq 28.12$ instead of the separation into WCDW and LCDW) was performed. The solution in the relevant deep-water range was not significantly different from the version using AABW sublayers. As the direct measurement constraints on $\mathrm{AABW}$ at $30^{\circ} \mathrm{S}$ and $4.5^{\circ} \mathrm{S}$ are relatively strong (Table 8 ) and well repro- duced in both solutions, we conclude that the error due to the poor resolution in the deepest layer influences only the separation of the net flow within the AABW, but does not contribute significantly to the solution through the "ill conditioned" WSDW layer constraints themselves.

According to the results on the net meridional overturning, the southward NADW transport decreases from $25 \mathrm{Tg} \mathrm{s}^{-1}$ in the north to $19 \mathrm{Tg} \mathrm{s}^{-1}$ in the south. There is also a change in the vertical structure of the individual NADW sublayers with latitude. Near the equator the transport in the upper NADW layers pre- 

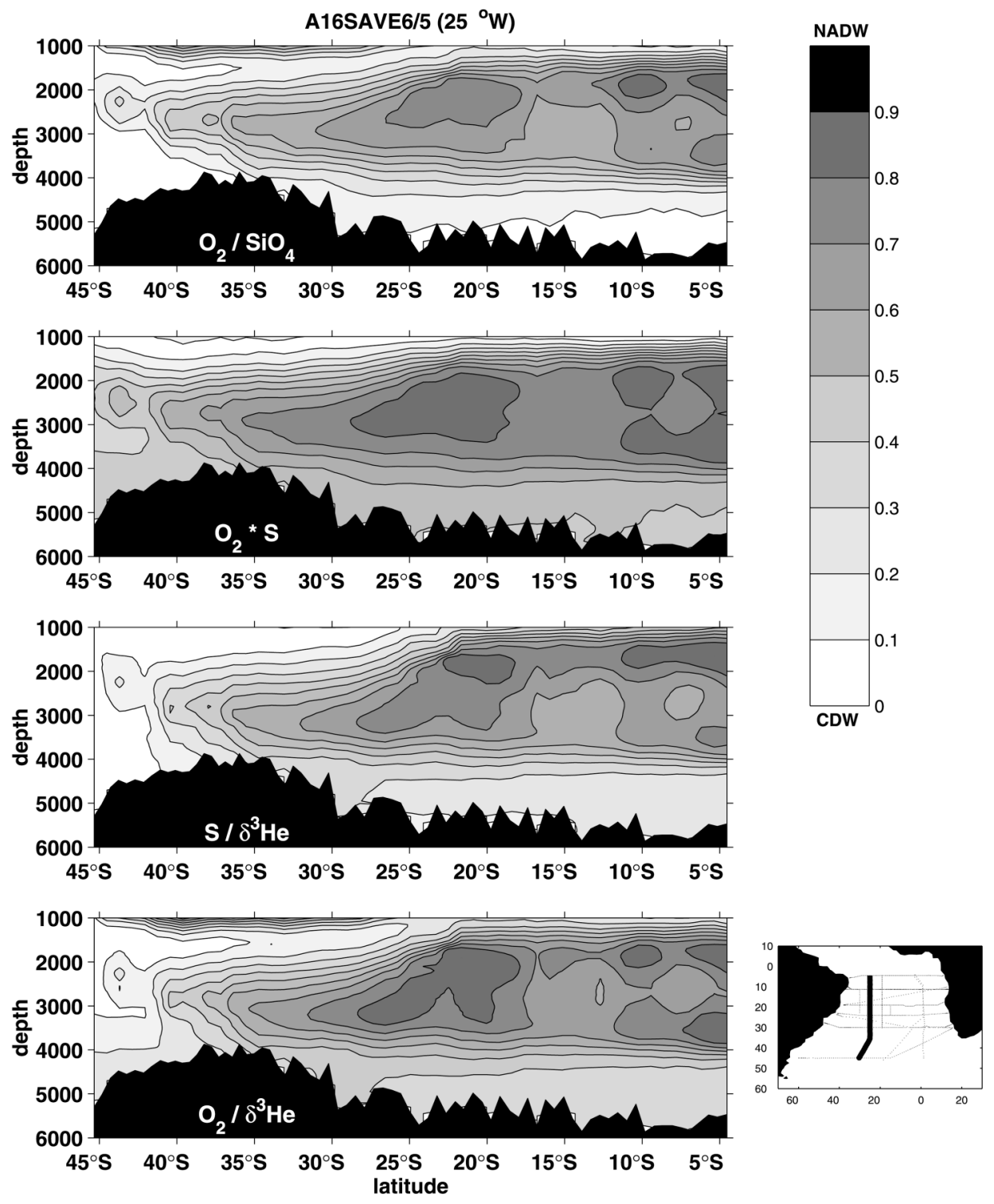

FIG. 16. Normalized property ratios at the meridional section A16 at $25^{\circ} \mathrm{W}$. Higher values (dark) in the depth range 2000-4000 m represent younger NADW (oxygen/salinity rich and nutrient/helium poor), lower values (light) denote older deep water with $\mathrm{CDW}$ signature.

dominates, whereas the relative contribution of the lower NADW increases to the south (see also Friedrichs et al. 1994).

\section{Zonal transports}

The resulting zonal mass transports in the whole NADW layer are shown in Fig. 15a. They were divided up horizontally into separate bands according to changes in flow direction and/or strength obtained from the shape of the corresponding cumulative transport curve. Figure 14 illustrates the separation method for the example of section A16 for the Middle NADW (MNADW) layer. Persistent zonal transport bands are found in certain latitude belts. In particular, we obtain an eastward transport in the Brazil Basin between $20^{\circ}$ and $25^{\circ} \mathrm{S}$. This flow begins near the Vitoria-Trindade Ridge and continues to the Rio de Janeiro Fracture Zone in the MAR. To the north of this eastward transport, deep water returns to the west between $10^{\circ}$ and $20^{\circ} \mathrm{S}$. An additional band with eastward direction occurs just north of $10^{\circ} \mathrm{S}$. These features obtained from the inverse model generally agree with the patterns found by measurements with deep floats (Hogg and Owens 1999; Hogg 2001). The mean depth of the float measurements was about $2500 \mathrm{~m}$, corresponding to the center of the MNADW layer. When comparing the zonal transports in different sublayers of the NADW, the highest values are found in the MNADW 

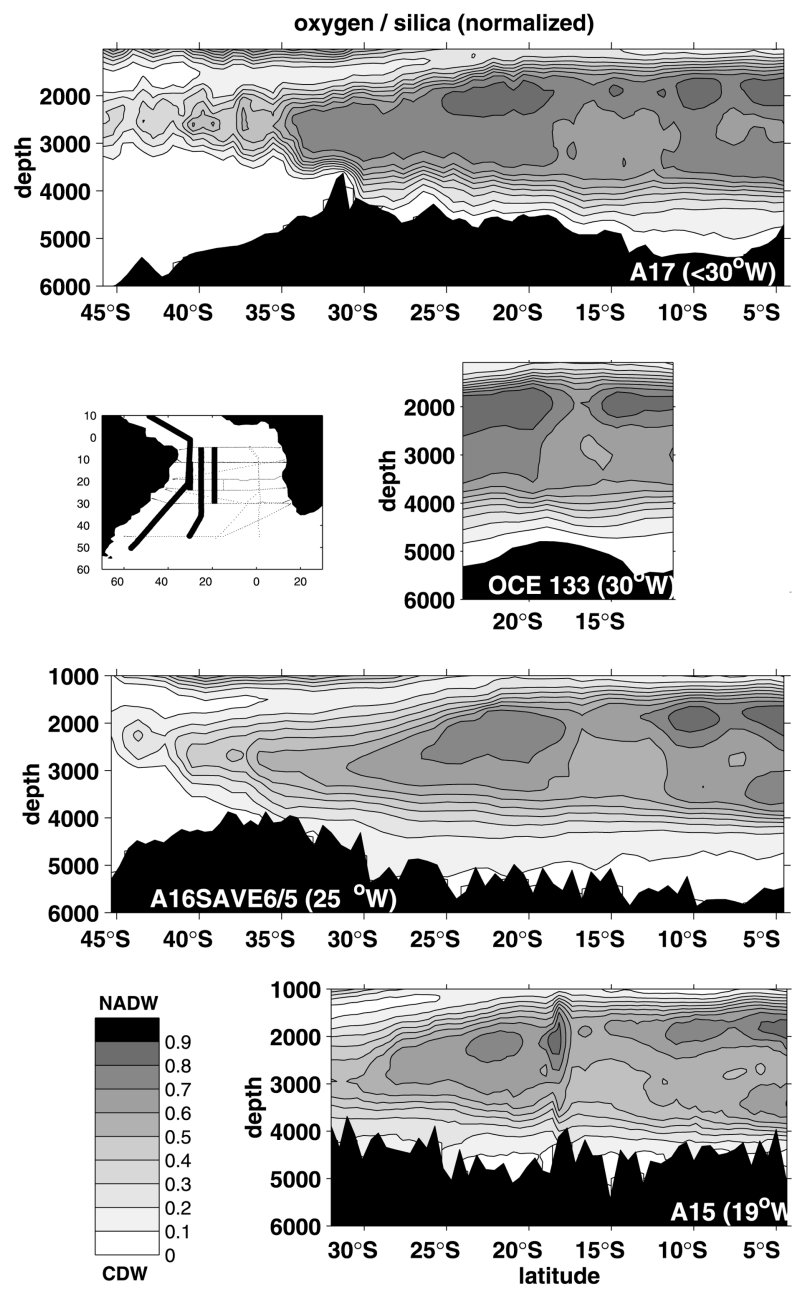

FIG. 17. Normalized oxygen/silica ratio at the meridional section A 15 at $19^{\circ} \mathrm{W}$ (bottom), at the meridional section A16 at $25^{\circ} \mathrm{W}$ (middle) and at the meridional section A17 west of $30^{\circ} \mathrm{W}$ (top). Higher values (dark) in the depth range 2000-4000 m represent younger NADW (oxygen rich and nutrient poor), lower values (light) denote older deep water with CDW signature. The maximum in section A15 at $18^{\circ} \mathrm{S}$ is an eddy originating in the DWBC where equally high values can be found. The more recent A17 data were not included in this inversion (for details see Mémery et al. 2000).

(Fig. 15c). In all layers the eastward flow can be observed up to the western flank of the MAR, even in the deepest NADW layer (OLNADW in Fig. 15d; see appendix section $\mathrm{C}$ ).

Due to the noise in the data, the separation latitude can be seen as an approximate boundary between the flow regimes only. Especially the width of the " $20^{\circ}$ $25^{\circ} \mathrm{S}$ " band represents the core of this eastward motion. The flow itself can be broader, depending on the interpretation of the noise at its boundaries (around $18^{\circ}$ and $26^{\circ} \mathrm{S}$ in Fig. 14). This is also the case for the float data. Here we want to direct the reader's attention to the noise in the direction of the float velocities, averaged around $25^{\circ} \mathrm{W}$, especially near $19^{\circ} \mathrm{S}$ (Hogg 2001, Plate 4.5.8). The approximate separation latitude for the $25^{\circ} \mathrm{W}$ sec- tion near depth $2500 \mathrm{~m}$ is at about $18^{\circ}-19^{\circ} \mathrm{S}$ in the float results (Hogg and Owens 1999; Hogg 2001) as well as in model results (Treguier et al. 2002, manuscript submitted to J. Phys. Oceanogr.).

What specific water masses are carried by these zonal flows, with the two water masses NADW and CDW existing in the same density range? The eastward flow between $20^{\circ}$ and $25^{\circ} \mathrm{S}$ consists of relatively young NADW. It is characterized by its maximum in oxygen and salinity and by low concentrations in silica, phosphate, and terrigenic helium compared with the high concentrations of nutrients and $\delta^{3} \mathrm{He}$ of the CDW (Fig. 9).

Good indicators for the separation of NADW, originating directly from the DWBC and the older deep water that has undergone more mixing with $\mathrm{CDW}$, are normalized ratios of salinity or oxygen and nutrients or $\delta^{3} \mathrm{He}$ (e.g., $\mathrm{O}_{2} / \mathrm{SiO}_{4}$ as shown in Fig. 16).

The exact values of these ratios are not essential here (they are normalized and have values between 0 and 1), but the locations of minima and maxima at the $25^{\circ} \mathrm{W}$ section clearly show properties of the NADW originating from the western boundary (high values) at about $22^{\circ} \mathrm{S}$ and of the older deep water (low values) in the region of the westerly flow to the north of $20^{\circ} \mathrm{S}$ (Fig. 16). Such water mass signatures correspond to the zonal flows obtained from the inverse model and can be recognized not only in the $25^{\circ} \mathrm{W}$ section, but can also be found in the other three meridional sections in the western South Atlantic (Fig. 17).

In addition to the broad tongue of older deep water around $15^{\circ} \mathrm{S}$ a core of older deep water is seen at about $7^{\circ} \mathrm{S}$, centered around $2800 \mathrm{~m}$ (Figs. 16, 17). This older deep-water core corresponds to a shallow band of eastward motion in the middle and upper NADW layers (Figs. 15b,c) and separates the westward-flowing, newer NADW at $10^{\circ} \mathrm{S}$ and at the northern edge of the sections. The prominent second large core of newer NADW between $20^{\circ}$ and $25^{\circ} \mathrm{S}$, corresponding to the eastward flow obtained from the inverse model, extends throughout the western South Atlantic in the ratio sections (Fig. 17). This eastward flow of younger NADW can be seen even at $15^{\circ} \mathrm{W}$, just west of the MAR, indicated by a low value of the product $\delta^{3} \mathrm{He} \cdot \mathrm{PO}_{4}$ in a depth range that reaches down to $3500 \mathrm{~m}$ (not shown).

A similar pattern can be found in the meridional distribution of oxygen on several density surfaces within the NADW at the $25^{\circ} \mathrm{W}$ A 16 section (Talley and Johnson 1994) and also in the corresponding zonal mean flow from current meter and RAFOS float data (Hogg 2001). There is a fairly good agreement between the patterns of oxygen concentrations, the directly observed flow, and the results of the inversion. A similar flow structure was found near the South American coast in the more recent results obtained from the section A17, where a westward flow returns low-oxygen deep water to the western boundary between $11^{\circ}$ and $17^{\circ} \mathrm{S}$ and where an eastward escape of oxygen-rich NADW occurs between 


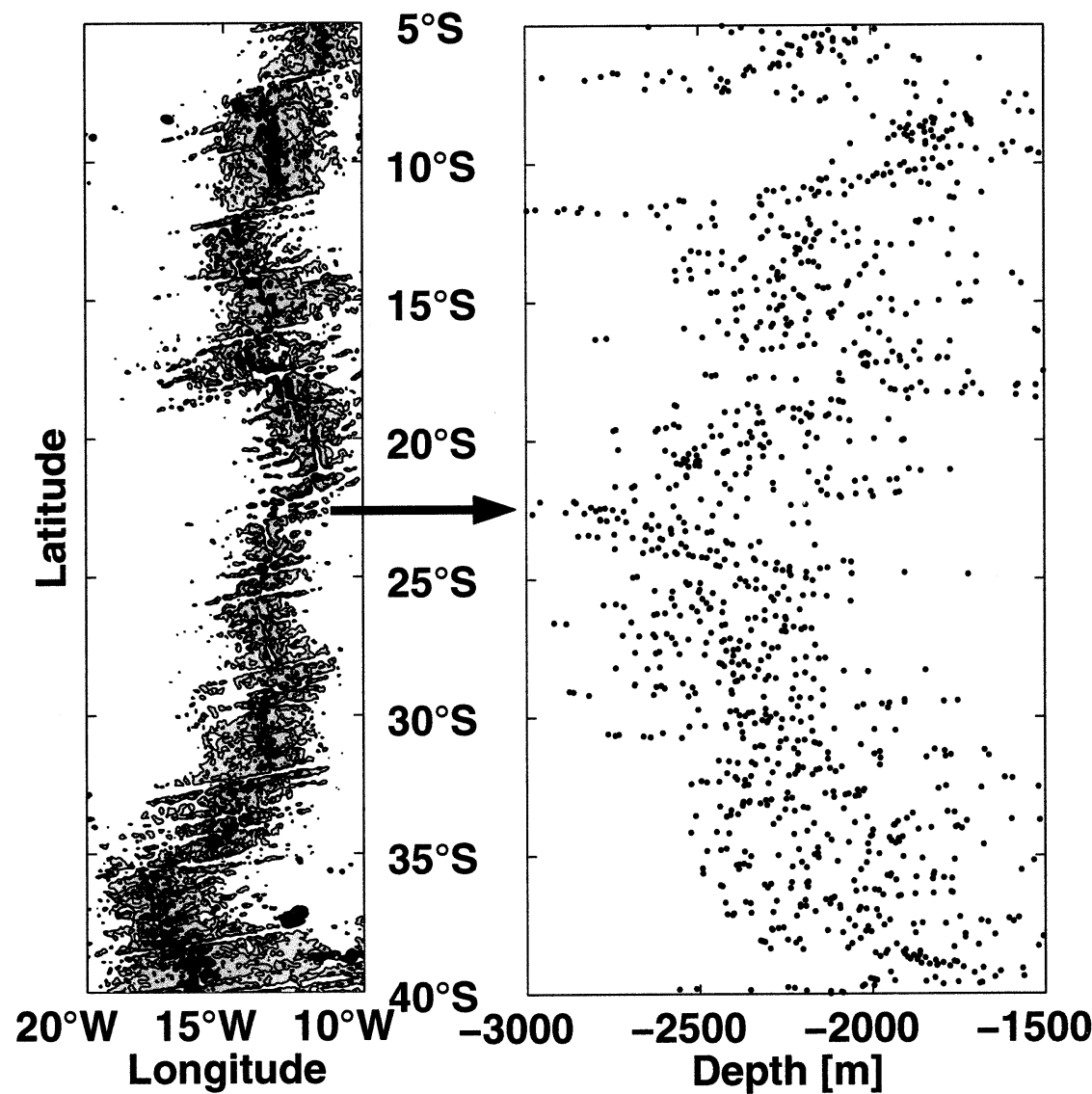

FIG. 18. (left) Topography of the Mid-Atlantic Ridge (MAR) from TOPEX_-dataset (Smith and Sandwell 1997, version 6.2); black: depth $<2500 \mathrm{~m}$, white: depth $>3300 \mathrm{~m}$, gray: 2500 $3300 \mathrm{~m}$, divided at $3000 \mathrm{~m}$; (right) The depths of the shallowest point of each approximately $5^{\circ}$ wide zonal strip of the full resolved (2') TOPEX topography along the MAR. The arrow represents the latitude of the Rio de Janeiro Fracture Zone.

$8.5^{\circ}$ and $10^{\circ} \mathrm{S}$ (Wienders et al. 2000; Mémery et al. 2000). Section A17 was not included in this inversion, but the oxygen/silica ratios (Fig. 17) mirror the characteristic water mass distributions of the sections farther east.

\section{Conclusions}

We focus on four results in our conclusions. First, the incorporation of additional tracers, compared to earlier studies, allow an improved and more detailed description of deep-water masses in the South Atlantic. In addition, the use of neutral surfaces as boundaries provides a better representation of water masses, particularly in the transition region between the subtropical and the subpolar South Atlantic.

Second, the inverse-model results clearly indicate a robust structure of coherent zonal current bands with considerable transports. The zonal flows appear to be important components of the thermohaline circulation in this part of the global ocean that are bound to influence the modification of water masses transiting the
South Atlantic. In particular, the broad band of eastward flow between $20^{\circ}$ and $25^{\circ} \mathrm{S}$ within the NADW, which appears to originate in the DWBC along the western boundary, could well supply the "Namib Col Current" (Warren and Speer 1991) extending to the Namib Col, a gap in the Walvis Ridge between the Angola and Cape Basins near $22^{\circ} \mathrm{S}$. This is also the latitude range where the minimum depth of the MAR, obtained from satellite altimetry and ship depth soundings (Fig. 18), is deepest, reaching $2500 \mathrm{~m}$ on average (versus $2000 \mathrm{~m}$ farther north), and where the Rio de Janeiro Fracture Zone (RJFZ) of the MAR is found near $22^{\circ}$. Using the SeaBeam system Ledwell et al. (2000) found the shallowest sill of the RJFZ on the western side of the MAR near $22.7^{\circ} \mathrm{S}, 13^{\circ} \mathrm{W}$, at $3900 \mathrm{~m}$. The zonal transports obtained from the inverse model indicate that this could be the place where approximately $4 \mathrm{~Sv}$ of NADW cross the MAR from the Brazil Basin to the Angola Basin. The detailed analysis of the meridional WOCE section A14 at $9^{\circ} \mathrm{W}$, which is just to the east of the MAR, will provide more reliable information on the continuation of this zonal flow in the Angola Basin. Unfortunately 


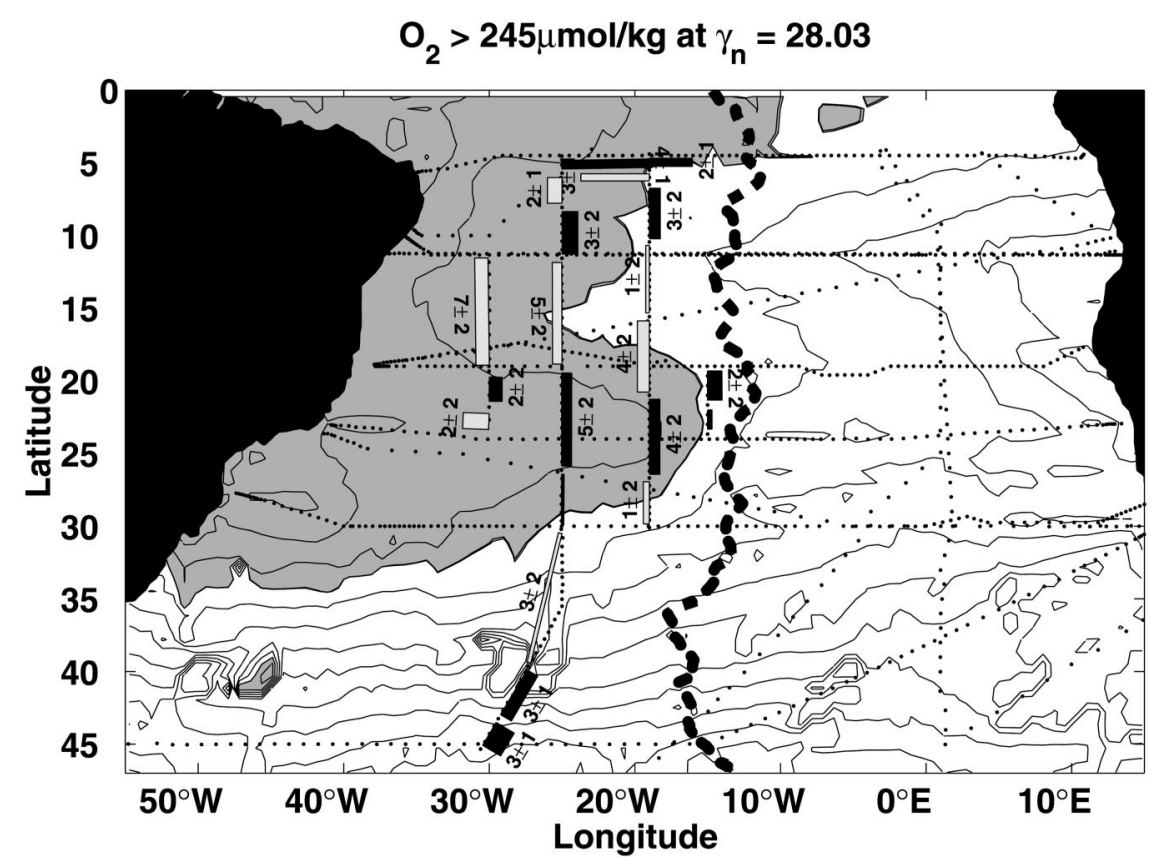

FIG. 19. Zonal transport $\left(\mathrm{Tg} \mathrm{s}^{-1}\right)$ in the MNADW (layers 7-8, as in Fig. 15) over the oxygen distribution on the neutral density surface of $\gamma_{n}=28.03$, which corresponds to the middle of the MNADW layer at about $2500 \mathrm{~m}$. The shaded area corresponds to $\mathrm{O}_{2}>245 \mu \mathrm{mol} \mathrm{kg}^{-1}$, the isoline spacing is $5 \mu \mathrm{mol} \mathrm{kg}{ }^{-1}$. The thick dashed line represents the axis of the MAR. The layers are defined by neutral density surfaces given in Table 4 .

these data were not yet available when the present analysis was done, but oxygen, temperature, and salinity distributions on that section had been described by Mercier and Arhan (1997). The middepth $\mathrm{O}_{2}$ maxima centered around $22^{\circ} \mathrm{S}$ indicate NADW coming from the western South Atlantic with the Namib Col Current. At the latitude of the Rio de Janeiro Fracture Zone, the middepth oxygen maximum extends down to the seafloor and gives evidence of bottom-water flow through the fracture zone (Mercier et al. 2000).

Third, we note a good correspondence of the present inverse-model results with the tracks of deep floats where these are available, and also with recent results of general circulation models. The overall float track patterns of zonal transports near $20^{\circ} \mathrm{S}$ found by Hogg and Owens (1999) are consistent with the transports obtained from the inverse model. In the interior of the Brazil Basin the " $2500 \mathrm{~m}$ float" motion was mainly zonal, alternating in direction on an apparent scale of roughly $500 \mathrm{~km}$ (though finer scales could not be resolved due to the limited number of float observations; N. G. Hogg 2001, personal communication). The centers of the mean zonal flow near depth $2500 \mathrm{~m}$ calculated from floats between $22^{\circ}$ and $30^{\circ} \mathrm{W}$ (Treguier et al. 2002) are at $22^{\circ}$ and $12^{\circ} \mathrm{S}$ for the eastward flow and at $15^{\circ}$ and $7^{\circ} \mathrm{S}$ for the westward motion. At the longitude and depth corresponding to the float observations $\left(25^{\circ} \mathrm{W}\right.$, MNADW, Fig. 14), the centers of the eastward flow are at $42^{\circ} \mathrm{S}, 22.5^{\circ} \mathrm{S}$, and $11^{\circ} \mathrm{S}$ and north of $6^{\circ} \mathrm{S}$, the westward moving bands are centered at $35^{\circ} \mathrm{S}, 15^{\circ} \mathrm{S}$, and $7^{\circ} \mathrm{S}$. Ex- cept for the southernmost bands, which are out of the float domain, the centers of the flow regimes correspond well with the float data. The meridional scale of the zonal bands in our study depends on the treatment of the noise when choosing the separation latitude (discussed in previous chapter). The scale for the most robust signal, the " $20^{\circ}-25^{\circ} \mathrm{S}$ " band, is at least $550 \mathrm{~km}$, but can be twice as much if one takes into account the noisy regions around the separation latitudes. The meridional scales for all the other flow regimes are around $500 \mathrm{~km}$ or smaller.

Also, both the comparisons with the high resolution $\left(1 / 4^{\circ}\right)$ Parallel Ocean Climate Model (Stammer et al. $1996)$ and with the coarse-resolution $\left(1.6^{\circ}\right.$ lat, $1.8^{\circ}$ lon $)$ model by England and Garçon (1994), show a similar eastward motion of NADW originating from the DWBC near $20^{\circ} \mathrm{S}$ (see also Stramma and England 1999, their Fig. 9).

Finally, we return to the question raised in the introduction: Is the real flow Wüstian, that is, following the axis of a property tongue, or does it go along the boundary of the tongue? In Fig. 19 the structure of the zonal flow in the MNADW layer is shown over the oxygen distribution on the neutral density surface of $\gamma_{n}=28.03$, corresponding to the middle of the MNADW layer at about $2500 \mathrm{~m}$. There is no unique answer for the whole South Atlantic, but the eastward flow pattern between $20^{\circ}$ and $25^{\circ} \mathrm{S}$ appears to correspond to the high oxygen pattern, confirming a Wüstian flow there. The same would still be true if the separation limits for the east- 
ward flowing band around $22.5^{\circ} \mathrm{S}$ would be chosen farther apart (as suggested by our first-order "objective" separation obtained directly from the filtered cumulative transport-Fig. 14). The axis of this band is still in the tongue. To change the conclusion and produce a nonWüstian flow, one would expect opposite direction of flow on northern and southern boundaries of the tongue, resulting in a flow around the tongue instead of in the axis of the tongue. We did not find any evidence for such flow patterns in our results.

Acknowledgments. The assistance of the Department of Marine Physics of the Institut für Meereskunde at Kiel University in observations and data processing was much appreciated. We are grateful to all the WOCE PIs and other scientists who permitted the use of their data, either by making them available directly or through data centers, and to J. Ledwell for contributing new SEABEAM results. We also benefitted from discussions with N. Hogg, W. Zenk, W. Roether, and C. Rüth. The study was supported by the Ministry of Science and Technology, Germany (BMBF, Fkz.: 03F0121A, 03F0050D, 03F0157A) and by Grant Number OC\#-9911148 from the National Science Foundation.

\section{APPENDIX}

\section{Water Masses in the South Atlantic}

\section{a. $A A I W$}

In the entire South Atlantic the salinity minimum of the AAIW can be seen at depths shallower than 1000 $m$ (black $\nabla$ in Figs. 3 and 4). The corresponding salinities are lower than $34.6 \mathrm{psu}$. At $25^{\circ} \mathrm{S}$ it is centered around the neutral density surface $\gamma_{n}=27.4$. Toward the north the salinity minimum is at higher neutral density in the range $\gamma_{n}=27.4-27.5$, whereas to the south of $25^{\circ} \mathrm{S}$ it is found at $\gamma_{n}=27.35-27.4$.

The corresponding oxygen maximum of the AAIW is only marked south of approximately $23^{\circ} \mathrm{S}$ with concentrations $>190 \mu \mathrm{mol} \mathrm{kg} \mathrm{kg}^{-1}$. In both the western (red $\triangle$ in Fig. 4) and eastern basin (not shown) it is found just above the AAIW salinity minimum in the density class $\gamma_{n}=27.4-27.5$. Close to the western boundary the $\mathrm{O}_{2}$ maximum of AAIW can be found as far north as $19^{\circ} \mathrm{S}$ in section A09 (not shown). Farther north it is absent in the whole A08 section at $11^{\circ} \mathrm{S}$ (Fig. 3).

In agreement with You (1999) the core of the AAIW was chosen to be the density layer of the salinity minimum or $\gamma_{n}=27.40$. This also corresponds to the potential density $\sigma_{\theta}=27.25$ used by Roether and Putzka (1996). Based on all these properties the complete AAIW layer, as distinguished from the overlying surface water and underlying UCDW, was chosen in the neutral density class $\gamma_{n}=27.15-27.55$. This range is similar to the potential density range $\sigma_{\theta}=27.0-27.4$ used by Talley (1996).

\section{b. $U C D W$}

The characteristic extrema of the UCDW are a $\theta$ minimum, $\mathrm{O}_{2}$ minimum, $\delta^{3} \mathrm{He}$ maximum, $\mathrm{SiO}_{4}$ maximum, and also localized minima in $\mathrm{CFCs}$ or $\mathrm{CCl}_{4}$, respectively. The most distinct signature is the silica maximum, with concentrations decreasing from more than $50 \mu \mathrm{mol} \mathrm{kg} \mathrm{kg}^{-1}$ at $30^{\circ} \mathrm{S}$ (A10) along the path of UCDW to the north. At $11^{\circ} \mathrm{S}$ the silica concentrations are still $>32 \mu \mathrm{mol} \mathrm{kg}{ }^{-1}$ throughout the whole section A08 in a layer about $400 \mathrm{~m}$ thick $\left(\gamma_{n}=27.5-27.7\right)$ and centered around depth $1000 \mathrm{~m}\left(\gamma_{n}=27.6\right.$ in Fig. 3, green $\left.\triangle\right)$. The northward reduction of the silica maximum is due to the influence of the NADW from below.

The temperature minimum (dark blue $\nabla$ ) of the UCDW can be seen only locally at the western boundary in the Brazil Basin (Fig. 3) and in the Argentine Basin (Fig. 4) in the same density layer as the silica maximum. Similar to the oxygen maximum of the AAIW, the oxygen minimum of UCDW is found only to the south of $23^{\circ} \mathrm{S}$ (red $\nabla$ in the Fig. 4). It is mostly shallower than the $\mathrm{SiO}_{4}$ maximum. Directly at the western boundary the $\mathrm{O}_{2}$ minimum of UCDW could be found as far north as $11^{\circ} \mathrm{S}$ in the Oceanus 133 section (not shown).

Due to its southern ACC origin the UCDW has high $\delta^{3} \mathrm{He}$ concentrations, decreasing to the north. This $\delta^{3} \mathrm{He}$ maximum is coincident with the silica maximum in all sections. In the northern Brazil Basin they can be found in a neutral density range of $\gamma_{n}=27.55-27.7$ (violet $\triangle$, Fig. 3), in the south reaching the higher density of $\gamma_{n}=27.88$.

Below the described characteristic extrema of UCDW, which has spent a long time without contact with the surface, there is a minimum of CFCs and $\mathrm{CCl}_{4}$ (light blue $\nabla)$. In the northern Brazil Basin it is located at $\gamma_{n}$ =27.7-27.8, approximately 200-300 m deeper than the corresponding $\mathrm{SiO}_{4}$ maximum (Fig. 3). Such a deepening of the CFC minimum was explained previously by an asymmetric diffusive erosion of this CFC minimum through diapycnal mixing (Rhein et al. 1995; Fine and Molinari 1988), because of the steeper vertical CFC gradient above the minimum compared with the gradient below. Therefore the CFC minimum is not a signature of the UCDW core and rather denotes the transition to the underlying UNADW.

The different extrema indicating the core of the UCDW are found in all sections, with the density of the core shifting from $\gamma_{n}=27.8$ (at approximately 1500 $\mathrm{m}$ ) at $30^{\circ} \mathrm{S}$ in the south to $\gamma_{n}=27.6$ (at $1000 \mathrm{~m}$ ) in the north. Depending on latitude the complete UCDW layer is located somewhat differently within the neutral density range $\gamma_{n}=27.55-27.88$. In the north the sublayer $\gamma_{n}=27.75-27.88$ represents the transition between UCDW and UNADW, with both the temperature maximum of the UNADW and the shallower CFC minimum of the UCDW being present. 


\section{c. $N A D W$}

This water mass can generally be characterized by $\theta$ and $S$ maxima and $\mathrm{SiO}_{4}$ and $\delta^{3} \mathrm{He}$ minima. Sublayers of NADW with different ages can be separated according to the distribution of $\mathrm{O}_{2}$ and $\mathrm{CFC}$ concentrations. The high salinities (black $\triangle$ ) at about $1700 \mathrm{~m}$ are characteristic for the Upper NADW (UNADW), accompanied by high $\mathrm{CCl}_{4}$ (light blue $\triangle$ ) and low $\mathrm{SiO}_{4}$ (green $\nabla)$ concentrations. At shallower levels there are minima of $\delta^{3} \mathrm{He}($ violet $\nabla)$ at approximately $1500 \mathrm{~m}$ pointing to the northern origin of the NADW, with very low concentrations of terrigenic helium compared to the $\delta^{3} \mathrm{He}$ maximum of UCDW at $1000 \mathrm{~m}$. In the western part of the section in the Brazil Basin the high temperatures (dark blue $\triangle$ ) also characterize this water mass. This shallow part of the Upper NADW was also named Shallow Upper NADW (SUNADW) by Rhein et al. (1995) or Upper Labrador Sea Water by Pickart (1992).

In the Brazil Basin, just below $2000 \mathrm{~m}$, high oxygen concentrations (red $\triangle$ ) seem to indicate the upper part of the Middle NADW (MNADW), which originates from Labrador Sea Water (LSW). In the lower, much older MNADW part, which is derived mostly from Gibbs Fracture Zone water, an $\mathrm{O}_{2}$ and $\mathrm{CCl}_{4}$ minimum can be found at approximately $2500 \mathrm{~m}$ (red and light blue $\nabla$ in Fig. 3 and northern part of Fig. 4).

The deepest NADW sublayer, the "Overflow Lower" NADW (OLNADW: according to Rhein et al. 1995), has the characteristics of a relatively young water mass with high $\mathrm{CCl}_{4}$ and $\mathrm{O}_{2}$ concentrations (red and light blue $\triangle$ ), similar to the UNADW, accompanied again with a minimum in $\delta^{3} \mathrm{He}$ (violet $\nabla$ ). Both maxima indicate the origin from one of the northern source water masses produced by convective renewal [Denmark Strait overflow water (DSOW)].

The following considerations lead to the choice of NADW boundaries. The density range occupied by the NADW is thicker in the north than in the south. For the UCDW/NADW boundary, a neutral density layer between $\gamma_{n}=27.70$ and 27.75 appears appropriate to the north of $11^{\circ} \mathrm{S}$. It corresponds approximately to the potential density $\sigma_{1}=32.15$ used previously by other authors as an upper NADW boundary in the equatorial western Atlantic (Rhein et al. 1995; Stramma 1991) or to the almost identical $\sigma_{2}=36.65$ used by McCartney (1993) in the same region. The choice of a deeper boundary would miss part of the warm UNADW; a shallower boundary would incorporate the whole CFCminimum water of the UCDW in the NADW layer. The influence of the CDW increases to the south along the NADW path, and the water at the upper NADW boundary becomes heavier (the boundary shifts to higher densities with increasing latitude). In the DWBC at $30^{\circ} \mathrm{S}$ the upper NADW is found below $\gamma_{n}=27.80$. South of $30^{\circ} \mathrm{S}$ and in the interior of the basin this density range is occupied mostly by UCDW.

In the northern and middle Brazil Basin different sub- layers of NADW can be observed. Away from the DWBC this differentiation by extrema can be used only north of $25^{\circ} \mathrm{S}$. Within the DWBC some of the NADW sublayers can be observed also to the south of this latitude. The upper boundary of the UNADW layer is also the upper boundary of the whole NADW layer. The UNADW layer contains in its upper portion a $\theta$ maximum (around $\gamma_{n}=27.8$ ), and a deeper $\mathrm{SiO}_{4}$ minimum and CFC maximum. The lower boundary between the salinity maximum of the UNADW and the $\mathrm{O}_{2}$ maximum of the underlying MNADW layer varies significantly (mainly in the meridional direction). An average value of $\gamma_{n}=27.98$ is defined as the interface for the UNADW/MNADW boundary.

Using the described vertical changes in oxygen concentration within the NADW, we determine the density classes of the cores of the corresponding NADW sublayers [LSW, LNADW-old, and OLNADW]. The part of NADW immediately beneath UNADW carries the signature of the oxygen-rich LSW. The corresponding $\mathrm{O}_{2}$ maximum between 1900 and $2400 \mathrm{~m}$ defines the LSW layer within the neutral density range of $\gamma_{n}=$ 27.98-28.03. The lower part of MNADW has low values of oxygen and CFC, the "old" LNADW. The corresponding $\mathrm{O}_{2}$ and $\mathrm{CCl}_{4}$ minima, partially accompanied by a local $\delta^{3} \mathrm{He}$ maximum, are found at approximately $2750 \mathrm{~m}$ or $\gamma_{n}=28.05$. The old LNADW layer covers the density range $\gamma_{n}=28.03-28.07$.

The deepest NADW component is the OLNADW. Its $\mathrm{O}_{2}$ maximum and high CFC concentrations can be found around $3500 \mathrm{~m}$. The boundary between the OLNADW and the old LNADW layer is the neutral density surface $\gamma_{n}=28.07$. The lower boundary to the underlying LCDW will be described in the following.

\section{d. $A A B W$}

In the Brazil Basin the mixture of water masses below the NADW is often described by the name Antarctic Bottom Water (AABW). It consists of LCDW and WSDW. Most of the properties of these water masses differ only slightly and do not allow a clear separation. Temperature and salinity decrease almost steadily to the bottom, whereas the silica concentration increases. This results in the near-bottom extrema seen in Figs. 3 and 4. Another property that can be used to separate the $\mathrm{AABW}$ components is the CFC concentration. The younger WSDW possesses higher CFC concentrations (Bullister 1989), compared with the older LCDW, which carries little or no anthropogenic tracers.

In the Brazil Basin a $\mathrm{CCl}_{4}$ minimum can be found around $4000 \mathrm{~m}$ in the $11^{\circ} \mathrm{S}$ (Fig. 3, light blue $\nabla$ ) and the $19^{\circ} \mathrm{S}$ sections, visible also in the northern part of Fig. 4. Vertically it is located between the higher CFC values of NADW and WSDW and is therefore an indicator of the core of LCDW. In section A08 at $11^{\circ} \mathrm{S}$ this $\mathrm{CCl}_{4}$ minimum corresponds to the $\gamma_{n}=28.18$ neutral density surface and farther south in the zonal section 
A09 $\left(19^{\circ} \mathrm{S}\right.$, not shown $)$ to $\gamma_{n}=28.15$. Still farther south at $30^{\circ} \mathrm{S}(\mathrm{A} 10)$ the $\mathrm{CCl}_{4}$ minimum of the LCDW is shallower, at approximately $\gamma_{n}=28.09$ just below the OLNADW. It is horizontally restricted to the region west of the Rio Grande Rise and over the western flank of the MAR.

Below this $\mathrm{CCl}_{4}$ minimum $\mathrm{CFC}$ concentrations increase almost continuously to the bottom. The only exception is section A09 along $19^{\circ} \mathrm{S}$ where a detached $\mathrm{CCl}_{4}$ maximum can be found around the neutral density surface of $\gamma_{n}=28.24$. In all zonal sections at $11^{\circ}$ and $19^{\circ} \mathrm{S}$ the highest abyssal $\mathrm{CCl}_{4}$ concentrations are located near the continental rise, whereas in section $\mathrm{A} 10$ at $30^{\circ} \mathrm{S}$ the local abyssal $\mathrm{CCl}_{4}$ maxima can be found in the deep Vema Channel (west of Rio Grande Rise) and in the western part of the Hunter Channel extension (at the eastern flank of the Rio Grande Rise).

Traditionally the 1.9 or $2.0^{\circ} \mathrm{C}$ isotherm is used as an AABW/NADW boundary (Speer and Zenk 1993). Reid et al. (1977) identified the AABW/NADW boundary in the South Atlantic by a strong vertical density gradient. They described such a level with high static stability or Brunt-Väisälä buoyancy frequency (see Fofonoff 1985) by $\sigma_{4}=45.90-45.95$. Reid's level corresponds to $\gamma_{n}$ $=28.135-28.175$, with a temperature $\theta=1.5^{\circ} \mathrm{C}$, and is therefore deeper than the traditional $\theta=2.0^{\circ} \mathrm{C}$, at $\sigma_{4}$ $=45.85-45.87$ or $\gamma_{n}=28.10-28.11$. According to the $\mathrm{CCl}_{4}$ distribution described above, the deep level used by Reid et al. (1977) would be located in the $\mathrm{CCl}_{4}$ minimum of LCDW.

Unfortunately there is no single density that describes the boundary between the $\mathrm{CCl}_{4}$ minimum of LCDW and $\mathrm{CCl}_{4}$ maximum of OLNADW. It varies depending on latitude and can be seen as $\gamma_{n}=28.135$ at $11^{\circ} \mathrm{S}$, corresponding to the AABW-OLNADW boundary of $\sigma_{4}=45.90$ used by Rhein et al. (1995). Farther south at $19^{\circ} \mathrm{S}$ it is located around $\gamma_{n}=28.11$ or approximately $1.9^{\circ} \mathrm{C}$, which approaches the choice of Speer and Zenk (1993) for $30^{\circ} \mathrm{S}$. As a compromise, we choose the neutral density surface $\gamma_{n}=28.12$ with accompanying temperatures of $1.8^{\circ}-1.85^{\circ} \mathrm{C}$ and $\sigma_{4}=45.88$ for the whole region.

\section{REFERENCES}

Boebel, O., R. E. Davis, M. Ollitrault, R. G. Peterson, P. L. Richardson, C. Schmid, and W. Zenk, 1999: The intermediate depth circulation in the western South Atlantic. Geophys. Res. Lett., 26 (21), 3329-3332.

Böning, C., and P. Herrmann, 1994: Annual cycle of poleward heat transport in the ocean: Results from high-resolution modeling of the north and equatorial Atlantic. J. Phys. Oceanogr., 24, 91107.

Broecker, W. S., and T.-H. Peng, 1982: Tracers in the Sea. LamontDoherty Geological Observatory, Columbia University, 690 pp.

Bullister, J. L., 1989: Chlorofluorocarbons as time-dependent tracers in the ocean. Oceanography, 2, 12-17.

Coachman, L. K., and K. Aagaard, 1988: Transports through Bering Strait: Annual and interannual variability. J. Geophys. Res., 93 (C12), 15 535-15 539.
daSilva, A. M., C. C. Young, and S. Levitus, 1994: Algorithms and Procedures. Vol. 1, Atlas of Surface Marine Data 1994, NOAA Atlas NESDIS 6, $83 \mathrm{pp}$.

Defant, A., 1941: Quantitative Untersuchungen zur Statik und Dynamik des Atlantischen Ozeans. Wiss. Ergebn. Dt. Atl. Exp. "METEOR" 1925-1927. 6 (2), 191-260.

De Madron, X. D., and G. Weatherly, 1994: Circulation, transport and bottom boundary layers of deep currents in the Brazil Basin. J. Mar. Res., 52, 583-638.

Dickson, R. R., and J. Brown, 1994: The production of North Atlantic Deep Water: Sources, rates and pathways. J. Geophys. Res., 99 (C6), 12 319-12 341.

England, M. H., and V. C. Garçon, 1994: South Atlantic circulation in a World Ocean model. Ann. Geophys., 12, 812-825.

Fine, R. A., and R. L. Molinari, 1988: A continuous deep western boundary current between Abaco $\left(26.5^{\circ} \mathrm{N}\right)$ and Barbados $\left(13^{\circ} \mathrm{N}\right)$. Deep-Sea Res., 35A, 1441-1450.

Fofonoff, N. P., 1985: Physical properties of seawater: A new salinity scale and equation of state of seawater. J. Geophys. Res., 90 (C2), 3332-3342.

Friedrichs, M. A. M., M. S. McCartney, and M. M. Hall, 1994: Hemispheric asymmetry of deep water transport modes in the western Atlantic. J. Geophys. Res., 99 (C12), 25 165-25 179.

Fuglister, F. C., 1960: Atlantic Ocean Atlas of Temperature and Salinity Profiles and Data from the International Geophysical Year of 1957-1958. Woods Hole Oceanographic Institution Atlas Series, Vol. 1, WHOI, 209 pp.

Ganachaud, A., 1999: Large scale oceanic circulation and fluxes of freshwater, heat, nutrients and oxygen. Ph.D. thesis, Massachusetts Institute of Technology-Woods Hole Oceanographic Institute Joint Program, $266 \mathrm{pp}$.

- and C. Wunsch, 2000: Improved estimates of global ocean circulation, heat transport and mixing from hydrographic data. Nature, 408, (6811), 453-457.

,$- \ldots$, J. Marotzke, and J. Toole, 2000: Meridional overturning and large-scale circulation of the Indian Ocean. J. Geophys. Res., 105 (C11), 26 117-26 134.

Garzoli, S. L., G. J. Goñi, A. J. Mariano, and D. B. Olson, 1997: Monitoring the upper southeastern Atlantic transports using altimeter data. J. Mar. Res., 55 (3), 453-481.

Gordon, A. L., 1986: Interocean exchange of thermocline water. $J$. Geophys. Res., 91 (C4), 5037-5046.

Hall, M. M., and H. L. Bryden, 1982: Direct estimates and mechanisms of ocean heat transport. Deep-Sea Res., 29 (3A), 339359.

—_ M. S. McCartney, and J. A. Whitehead, 1997: Antarctic Bottom Water flux in the equatorial western Atlantic. J. Phys. Oceanogr., 27, 1903-1926.

Hellerman, S., and M. Rosenstein, 1983: Normal monthly wind stress over the World Ocean with error estimates. J. Phys. Oceanogr., 13, 1093-1104.

Hogg, N. G., 2001: Quantification of the deep circulation. Ocean Circulation and Climate_Observing and Modelling the Global Ocean, G. Siedler, J. Church, and J. Gould, Eds., International Geophysics Series, Vol. 77, Academic Press, 259-270.

- and W. B. Owens, 1999: Direct measurement of the deep circulation within the Brazil Basin. Deep-Sea Res. II, 46, 335-353.

_, G. Siedler, and W. Zenk, 1999: Circulation and variability at the southern boundary of the Brazil Basin. J. Phys. Oceanogr., 29, $145-157$.

Holfort, J., and G. Siedler, 2001: The meridional oceanic transports of heat and nutrients in the South Atlantic. J. Phys. Oceanogr., 31, 5-29.

- K. M. Johnson, B. Schneider, G. Siedler, and D. W. R. Wallace, 1998: Meridional transports of dissolved inorganic carbon in the South Atlantic Ocean. Global Biochem. Cycles, 12, 479-499.

Jackett, D., and T. McDougall, 1997: A neutral density variable for the world's oceans. J. Phys. Oceanogr., 27, 237-263.

Larqué, L., K. Maamaatuaiahutapu, and V. Garçon, 1997: On the 
intermediate and deep water flows in the South Atlantic Ocean. J. Geophys. Res., 102, 12 425-12 440.

Ledwell, J. R., E. T. Montgomery, K. L. Polzin, L. C. St. Laurent, R. W. Schmitt, and J. M. Toole, 1999: Evidence for enhanced

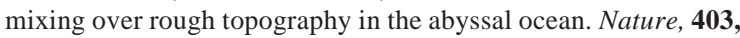
179-182.

- T. Donoghue, B. Guest, P. Lemmond, C. Sellers, and N. Cortes, 2000: Brazil Basin Tracer Release Experiment. WHOI Cruise Rep. R/V Knorr Cruise 161-6, 39 pp.

Lovelock, J. E., R. J. Maggs, and R. J. Wade, 1973: Halogenated hydrocarbons in and over the Atlantic. Nature, 241, 194-196.

Lux, M., H. Mercier, and M. Arhan, 2001: Interhemispheric exchanges of mass and heat in the Atlantic Ocean in January-March 1993. Deep-Sea Res. I, 48, 605-638.

Macdonald, A. M., 1993: Property fluxes at $30^{\circ} \mathrm{S}$ and their implications for the Pacific-Indian throughflow and the global heat budget. J. Geophys. Res., 98 (C4), 6851-6868.

_ 1998: The global ocean circulation: A hydrographic estimate and regional analysis. Progress in Oceanography, Vol. 41, Pergamon, 281-382.

__ and C. Wunsch, 1996: An estimate of global ocean circulation and heat fluxes. Nature, 382, 436-439.

Marin, F., and Y. Gouriou, 2000: Heat fluxes across $7^{\circ} 30 \mathrm{~N}$ and $4^{\circ} 30$ S in the Atlantic Ocean. Deep-Sea Res. I, 47, 2111-2139.

McCartney, M. S., 1993: Crossing of the equator by the deep western boundary current in the western Atlantic Ocean. J. Phys. Oceanogr., 23, 1953-1974.

Mémery, L., M. Arhan, X. A. Alvarez-Salgado, J. Messias, H. Mercier, C. G. Castro, and A. F. Rios, 2000: The water masses along the western boundary of the South and equatorial Atlantic. Progress in Oceanography, Vol. 47, Pergamon, 69-98.

Mercier, H., and M. Arhan, 1997: Two meridional hydrographic sections in the eastern South Atlantic Ocean (WHP lines A13 and A14). Int. WOCE Newslett., 28, 28-30.

—_, and P. Morin, 1997: Hydrography of the Romanche and Chain Fracture Zone. J. Geophys. Res., 102, 10 373-10 389.

_ , G. L. Weatherly, and M. Arhan, 2000: Bottom water throughflows at the Rio de Janeiro and Rio Grande Fracture Zones. Geophys. Res. Lett., 27, 1503-1506.

Orsi, A. H., G. C. Johnson, and J. L. Bullister, 1999: Circulation, mixing, and production of Antarctic Bottom Water. Progress in Oceanography, Vol. 43, Pergamon, 55-109.

Peterson, R. G., and T. I. Whitworth, 1989: The subantarctic and polar fronts in relation to deep water masses through the southwestern Atlantic. J. Geophys. Res., 94 (C8), 10 817-10 838.

Pickart, R. S., 1992: Water mass components of the North Atlantic deep western boundary current. Deep-Sea Res., 39, 1553-1572.

—_ N. G. Hogg, and W. M. Smethie Jr., 1989: Determining the strength of the deep western boundary current using the chlorofluoromethane ratio. J. Phys. Oceanogr., 19, 940-951.

Polzin, K. L., J. M. Toole, J. R. Ledwell, and R. W. Schmitt, 1997: Spatial variability of turbulent mixing in the abyssal ocean. Science, 276, 93-96.

Reid, J. L., 1989: On the total geostrophic circulation of the South Atlantic Ocean: Flow patterns, tracers and transports. Progress in Oceanography, Vol. 23, Pergamon, 149-244.

— W. W. D. Nowlin Jr., and W. C. Patzert, 1977: On the characteristics and circulation of the southwestern Atlantic Ocean. J. Phys. Oceanogr., 7, 62-91.

Rhein, M., 1994: The deep western boundary current: Tracers and velocities. Deep-Sea Res., 41, 263-281.

— L. Ltramma, and U. Send, 1995: The Atlantic Deep Western Boundary Current: Water masses and transports near the equator. J. Geophys. Res., 100 (C2), 2441-2457.

—_ - and G. Krahmann, 1998: The spreading of Antarctic Bottom Water in the tropical Atlantic. Deep-Sea Res. I, 45, 507527.

Rintoul, S. R., 1991: South Atlantic interbasin exchange. J. Geophys. Res., 96 (C2), 2675-2692.

Robbins, P. E., and J. M. Toole, 1997: The dissolved silica budget as a constraint on the meridional overturning circulation of the Indian Ocean. Deep-Sea Res. I, 44, 879-906.

Roether, W., and A. Putzka, 1996: Transient-tracer information on ventilation and transport of South Atlantic waters. The South Atlantic: Present and Past Circulation, G. Wefer et al., Eds., Springer Verlag, 83-104.

_- R. Well, A. Putzka, and C. Rüth, 1998: Component separation of oceanic helium. J. Geophys. Res., 103 (C12), 27 931-27946.

Rüth, C., 1998: Heliumisotopen- und Neon-Messungen im Südatlantik: Ozeanographische und geochemische Anwendungen. Ph.D. thesis, Institut für Umweltphysik, Universität Bremen, $117 \mathrm{pp}$.

-, R. Well, and W. Roether, 2000: Primordial ${ }^{3} \mathrm{He}$ in South Atlantic deep waters from sources on the mid-Atlantic ridge. Deep-Sea Res., 47, 1059-1075.

Saunders, P. M., and B. A. King, 1995: Oceanic fluxes on the WOCE A11 section. J. Phys. Oceanogr., 25, 1942-1958.

Schmid, C., G. Siedler, and W. Zenk, 2000: Dynamics of intermediate water circulation in the subtropical South Atlantic. J. Phys. Oceanogr., 30, 3191-3211.

Schmitz, W. J., 1995: On the interbasin scale thermohaline circulation. Rev. Geophys., 33, 151-173.

__ 1996a: On the World Ocean circulation: Vol. I, Some global features/North Atlantic circulation. WHOI Tech. Rep. WHOI96-03, $141 \mathrm{pp}$

_ 1996b: On the World Ocean circulation: Vol. II, The Pacific and Indian Oceans/A global update, WHOI Tech. Rep. WHOI96-08, 237 pp.

Servain, J., and S. Lukas, 1990: Climatic atlas of the Tropical Atlantic Wind Stress and Sea Surface Temperature 1985-1989. IFREMER, 133 pp.

__, F. Gohin, and A. Muzellec, 1993: Wind fields at the sea surface determined from combined ship and satellite altimeter data. $J$. Atmos. Oceanic Technol., 10, 880-886.

Smith, W. H. F., and D. T. Sandwell, 1997: Global seafloor topography from satellite altimetry and ship depth soundings. Science, 277, $1956-1962$.

Speer, K. G., and W. Zenk, 1993: The flow of Antarctic Bottom Water into the Brazil Basin. J. Phys. Oceanogr., 23, 2667-2682.

— , G. Siedler, and L. D. Talley, 1995: The Namib Col Current. Deep-Sea Res. I, 42, 1933-1950.

— J. J. Holfort, T. Reynaud, and G. Siedler, 1996: South Atlantic heat transport at $11^{\circ} \mathrm{S}$. The South Atlantic: Present and Past Circulation, G. Wefer et al., Eds., Springer Verlag, 105-120.

Stammer, D., R. Tokmakian, A. Semtner, and C. Wunsch, 1996: How well does a $14^{\circ}$ global circulation model simulate large-scale oceanic observations? J. Geophys. Res., 101 (C11), 25 779-25 811.

Stramma, L., 1991: Geostrophic transport of the South Equatorial Current in the Atlantic. J. Mar. Res., 49, 281-294.

— culation of the South Atlantic Ocean. J. Geophys. Res., 104 (C9), $20863-20883$.

Talley, L. D., 1996: Antarctic Intermediate Water in the South Atlantic. The South Atlantic: Present and Past Circulation, G. Wefer et al., Springer Verlag, 219-238.

- and C. Johnson, 1994: Deep, zonal subequatorial currents. Science, 263, 1125-1128.

Treguier, A.-M. N. G. Hogg, M. E. Maltrud, K. G. Speer, and V. Thierry, 2002: On the origin of the deep zonal flows in the Brazil Basin. J. Phys. Oceanogr., in press.

Trenberth, K. E., J. G. Olson, and W. G. Large, 1989: A global ocean wind stress climatology based on ECMWF analyses. NCAR Tech. Note $338+$ STR, 93 pp.

— W. W. Large, and J. G. Olson, 1990: The mean annual cycle in global ocean wind stress. J. Phys. Oceanogr., 20, 1742-1760.

Tsuchiya, M., L. D. Talley, and M. S. McCartney, 1994: Water-mass distributions in the western South Atlantic; a section from South Georgia Island (54S) northward across the equator. J. Mar. Res., $\mathbf{5 2 ,} 55-81$.

Warren, B. A., and K. G. Speer, 1991: Deep circulation in the eastern South Atlantic Ocean. Deep-Sea Res., 38 (Suppl.), 281-322. 
Weatherly, G. L., Y. Y. Kim, and E. A. Kontar, 2000: Eulerian measurements of the North Atlantic Deep Water Deep Western Boundary Current at $18^{\circ}$ S. J. Phys. Oceanogr., 30, 971-986.

Weiss, R. F., J. L. Bullister, R. H. Gammon, and M. J. Warner, 1985 Atmospheric chloroflouromethanes in the deep equatorial Atlantic. Nature, 314, 608-610.

Wienders, N., M. Arhan, and H. Mercier, 2000: Circulation at the western boundary of the South and Equatorial Atlantic: Exchanges with the ocean interior. J. Mar. Res., 58, 1007-1039.

Wunsch, C., 1978: The North Atlantic general circulation west of $5^{\circ} \mathrm{W}$ determined by inverse methods. Rev. Geophys. Space Phys. 16, 583-620.
Wüst, G., 1935: Schichtung und Zirkulation des Atlantischen ozeans. Das bodenwasser und die stratosphäre. Wiss. Ergebn. Dt. Atl. Exp. "METEOR" 1925-1927. 6, 1-288.

You, Y., 1999: Dianeutral mixing, transformation and transport of Antarctic Intermediate Water in the South Atlantic Ocean. DeepSea Res. II., 46, 393-435.

Zangenberg, N., and G. Siedler, 1998: The path of the North Atlantic Deep Water in the Brazil Basin. J. Geophys. Res., 103, 54195428.

Zenk, W., G. Siedler, B. Lenz, and N. G. Hogg, 1999: Antarctic Bottom Water flow through the Hunter Channel. J. Phys. Oceanogr., 29, 2785-2801. 